Anuario de la Facultad de Derecho. Universidad de Extremadura 36 (2020): 623-671

ISSN: 0213-988X - ISSN-e: 2695-7728

\title{
LA FISCALIDAD DEL MECENAZGO
}

\author{
THE TAXATION OF PATRONAGE
}

\begin{abstract}
ALEJo HeRnándeZ LAVAdo Centro de Estudios Borjanos de la Fundación "Fernando el Católico"
\end{abstract}

Recibido: 27/10/2020

Aceptado: 18/12/2020

\section{RESUMEN}

Es objeto del presente trabajo el análisis de la fiscalidad del mecenazgo, a raíz de la última reforma producida por el Real Decreto-ley 17/2020, de 5 de mayo. Otra reforma puntual, totalmente limitada en sus contenidos. Otra reforma, que no aborda ni resuelve los problemas que el mecenazgo tiene en España. Unos problemas, que son la causa de que siga sin generarse una auténtica mentalidad de mecenazgo. Por ello, en España una parte importante de la población civil sigue sin implicarse en actividades de interés general, sobre todo en actividades de interés cultural. Analizaremos los requisitos objetivos y subjetivos de la tributación de las cantidades donadas a entidades beneficiarias del mecenazgo. Un análisis, que haremos, tanto en el Impuesto sobre la Renta de las Personas Físicas, como en el Impuesto sobre Sociedades, valorando los aspectos positivos y negativos.

Dado que la situación actual está lejos de lo deseable, acabaremos indicando que pasos deberíamos dar para conseguir que lleguemos a tener en España una mentalidad de mecenazgo. Una mentalidad de mecenazgo, que sea un eficaz instrumento para proteger y potenciar los fines de interés general. Para proteger de forma especial la cultura y el patrimonio cultural, que es donde menos se está desarrollando en estos momentos el mecenazgo. 
Palabras clave: Mecenazgo, Mecenazgo cultural, Mecenazgo de la Iglesia, Mecenazgo de la nobleza, patrimonio cultural, patrimonio histórico, cultura, exenciones, beneficios fiscales, actividades de interés general.

\section{ABSTRACT}

The object of this work is the analysis of the taxation of patronage, following the latest reform produced by Royal Decree-Law 17/2020, of May 5. Another specific reform, totally limited in its contents. Another reform that does not address or solve the problems that patronage has in Spain. Some problems that cause this country to continue without generating a true patronage mentality. A country where an important part of the civilian population does not get involved in activities of general interest, especially in activities of cultural interest. We will analyze the objective and subjective requirements of the taxation of the amounts donated to beneficiary entities of the patronage. We do the analysis both in the personal income tax, and in the corporation tax, evaluating the positive and negative aspects.

Given that the current situation is far from desirable, we will end by indicating what steps we should take to ensure that we have a patronage mentality in Spain. A patronage mentality that is an effective instrument to protect and enhance the purposes of general interest. To protect culture and cultural heritage in a special way, which is where patronage is least developing at the moment.

Keywords: Patronage, Cultural Patronage, Patronage of the Church, Patronage of the nobility, cultural heritage, historical heritage, culture, exemptions, tax benefits, activities of general interest.

Sumario: Introducción. 1. Antecedentes del Mecenazgo. 1.1. Antecedentes remotos. 1.1.1. El más admirable. 1.1.2. El más normal. 1.2. Antecedentes próximos. 1.2.1. Antecedentes legislativos. 1.2.2. Últimas propuestas de reforma del mecenazgo. 2. Los fines de interés general y la justificación de los beneficios fiscales por desarrollar actividades de interés general. 3. Deducciones a que dan derecho las actividades de interés general financiadas con aportaciones de la sociedad civil. 3.1. Límites y problemas que genera la aplicación de los porcentajes de deducción. 3.2. Estructura de la tabla. 4. Donaciones con derecho a deducción. 4.1. Condiciones que han de reunir las deducciones para tener derecho a la deducción por mecenazgo. 4.1.1. Irrevocables. 4.1.2. Puras. 4.1.3. Simples. 4.2. Elenco de bienes y derecho que pueden ser donados. 5. Entidades 
beneficiarias del mecenazgo. 5.1. Entidades sin fines lucrativos a las que es de aplicación el régimen fiscal establecido en el título II de la ley 49/2002. 5.2. Entes públicos. 5.3. Entidades de carácter religioso. 6. Otras modalidades de mecenazgo. 6.1. Las Actividades prioritarias de Mecenazgo. 6.2. Los convenios de colaboración empresarial en actividades de interés general. 7. Consecuencias que puede generar la reforma del mecenazgo de 5 de mayo de 2020. 8. Propuestas de "lege ferenda" para conseguir potenciar el mecenazgo en España. 8.1. Medidas de promoción del mecenazgo. 8.2. Medidas incentivadoras en los aspectos fiscales del mecenazgo. 8.3. Eliminar la conflictividad y el malestar social que ha generado la aplicación de la Ley 49/2002 y la reforma del Impuesto de Sociedades.

\section{INTRODUCCIÓN}

La crisis económica iniciada a finales del año 2007, puso de relieve la dificultad de los entes públicos para cubrir todas las actividades de interés general, tanto en el campo social como en el cultural. La pandemia en la que estamos inmersos desde marzo de 2020, ha empeorado la situación, incrementando las personas y los bienes en situación de vulnerabilidad. La situación obliga de forma inaplazable a impulsar el mecenazgo, para paliar el desolador panorama que encontramos a nuestro alrededor.

En España no se acaba de conseguir, que el mecenazgo de las personas físicas alcance los niveles que son normales en el mundo anglosajón. En Inglaterra o Estados Unidos el peso del mecenazgo de las personas físicas, representa el 70\% frente al de las personas jurídicas. En España son las personas jurídicas las que llevan el grueso del mecenazgo. La mentalidad de mecenazgo, que existe en el mundo anglosajón, no existe en España, y tampoco parece fácil que llegue a existir, por el escaso esfuerzo que se hace desde los poderes públicos por generar dicha mentalidad de mecenazgo.

No vamos a entrar en aspectos, que son más próximos a la sociología, y a la psicología, que al derecho tributario. Lo que vamos a hacer, es analizar la fiscalidad del mecenazgo, sin distinguir el social del cultural. La legislación es única, para todo tipo de mecenazgo, no los distingue, y el propio ministerio de 
Cultura y Deporte y la Agencia Tributaria tampoco distinguen, ni desglosan, las partidas de uno y otro.

Siempre ha existido un mecenazgo de carácter social, o sea, de ayuda a los sectores más débiles de la sociedad: niños expósitos, enfermos, ancianos sin familia que les cuide, etc. pero históricamente el mecenazgo tiene su vínculo fundamental con la creatividad, y no con los sectores vulnerables. Es más, si buscamos la definición de mecenazgo en el Diccionario de la Real Academia Española de la Lengua, nos dice, que mecenazgo es la cualidad de mecenas, y a la vez, que mecenazgo es la protección o ayuda dispensada a una actividad cultural, artística o científica. No aparecen los fines de interés general, o de carácter social, como la defensa de los derechos humanos, las victimas de terrorismo, actos violentos, etc. En contradicción con esta definición, hoy tiene mayor relieve el mecenazgo social, que el cultural, artístico o científico. En estos momentos, es más valioso ayudar a resolver el problema del coronavirus, atender a los enfermos, y salvar vidas, que el hecho de, que se pinte un buen cuadro, se haga una buena escultura, se represente una buena opera, se restaure un importante bien de interés cultural, etc. Y este es otro de los problemas, que tiene el mecenazgo cultural en España: el mecenazgo social absorbe la mayor parte de los recursos, que el mecenazgo de la sociedad civil genera.

A lo anterior, hemos de añadir, que vivimos en un mundo en el que la economía, la generación de riqueza es lo único que importa, lo que lleva a que con frecuencia se oiga la pregunta déstas ruinas para que las vamos a conservar, qué dinero podemos ganar con ello? Ello es así, porque la sociedad no es conocedora del valor del patrimonio cultural, ni de la realidad de que, en torno a la cultura, y el patrimonio cultural se ha desarrollado una importante industria de gestión, uso, mantenimiento, etc. de bienes y actividades culturales. Y a ello se ha unido un fuerte incremento del turismo cultural. Las actividades comerciales, industriales y profesionales del mundo de la cultura, del patrimonio cultural y del turismo cultural, generan tanto en los países en desarrollo, como en los desarrollados un 
crecimiento económico sostenible ${ }^{1}$. Por tanto, para los que no son capaces de comprender la importancia de la cultura, y del patrimonio cultural como identidad de un lugar, los que no son capaces de valorar y por tanto estar dispuestos a contribuir al mecenazgo de la cultura y del patrimonio cultural, que tengan presente que hablamos de realidades, que son cada vez más generadores de unos importantes recursos económicos.

Por todo ello, actualmente el mecenazgo, es una preocupación importante en el mundo occidental, y en los países de nuestro entorno, especialmente en Inglaterra, Francia e Italia. Países que han realizado un esfuerzo importante para relanzar el mismo. En España llevamos muchos años escuchando cantos de sirena, sobre una nueva Ley de Mecenazgo, pero salvo el paso que han dado algunas comunidades autónomas, seguimos igual. De ello deriva la importancia de reflexionar sobre la normativa actual, y sobre una nueva ley de mecenazgo. Esperamos que nuestra contribución sea de alguna utilidad para ello.

\section{ANTECEDENTES DEL MECENAZGO}

Vamos a dividir este capítulo en dos partes. En la primera nos vamos a adentrar en la historia de occidente. La cultura a la que pertenecemos, para partiendo de Grecia y Roma, tomar consciencia de como el hombre lleva en Europa miles de años generando desde el altruismo y la generosidad un

1 De los datos de la página web del museo del Prado podemos comprobar que genera cerca de 4.000.00o de visitantes al año, con unos ingresos en 2018 por entradas de 19.200.00o euros, con lo que tiene un nivel de autosuficiencia económica cercano al 70\%. ¿̇qué riqueza generan en Madrid estos millones de visitantes? Máxime teniendo en cuenta que la mayor parte son de fuera de Madrid y muchos procedentes del extranjero. El impacto económico en alojamiento, restaurante, ocio, servicios de todo tipo y compras es enorme. https://www.museodelprado.es/actualidad/noticia/el-museo-delprado-atrae-a-mas-de-360000o/e141f71d-3638-ebdd-9606-9dc428483acd acceso por última vez el 25 de enero de 2020. Ettore Battelli, "I soggetti privati e la valorizzazione del patrimonio culturale" en PATRIMONIO CULTURALE PROFILI GIURIDICI E TECNICHE DI TUTELA a cura di Ettore Battelli, BarBara Cortese, andrea Gemma, antonella massaro. (Roma: Università degli Studi Roma Tre Dipartimento di Giurisprudenza, 2017), 72. Giuseppe Scanu, "Dalla leva fiscale regionale un possibile volano per la promozione del patrimonio culturale e lo sviluppo economico territoriale", Rivista trimestrale di diritto tributario $\mathrm{n}^{0}$ 2(2018): 407. Gianfrancesco Fidone,"Il ruolo dei privati nella valorizzazione dei beni culturali; dalle sponsorizzacioni alle forme di gestione”, En Aedon Rivista di arte e diritto on line número 1-2 (2012): 7. 
mecenazgo social y cultural. En la segunda parte nos adentraremos en un análisis más jurídico de los antecedentes legislativos más próximos a nosotros, como instrumento de interpretación de la actual normativa.

\subsection{ANTECEDENTES REMOTOS}

La palabra mecenazgo viene de la figura de Cayo Cilnio Mecenas. Un noble de origen etrusco, originario de Perugia (Italia), que mantuvo una fuerte amistad y colaboración política con el emperador César Augusto. Mecenas, se caracterizó por dar un importante apoyo económico a los artistas, fundamentalmente a los poetas, y entre ellos, nada menos que a Virgilio y Horacio, que escribieron obras en su honor. Mecenas, como tantos otros impulsores de las artes, y las letras de los últimos 2000 años, además de amar la poesía, y ser generoso y altruista, utilizó a los artistas a los que patrocinaba, para revalorizar su persona, su posición y la del Emperador Augusto. Lo mismo hicieron en el renacimiento italiano, tanto el Papa como las grandes familias de la época: Medici en Florencia; Farnesio en Parma²; Sforza en Milán; etc. Estas familias y otras más, apoyaron a artistas y literatos, que, con pinturas, esculturas, y obras literarias, enaltecían sus casas. A veces, incluso, incorporaban directamente en el cuadro, o en la obra escultórica, al donante y a su cónyuge.

Lo mismo sucede en el resto de Europa, según se extienden las ideas del renacimiento italiano. En concreto en España, ha sido la iglesia, la nobleza, y los comerciantes enriquecidos, y en el caso de Extremadura, los indianos y peruleros, según la localidad extremeña en la que nos encontremos, quienes, de forma más notable, han desarrollado históricamente el mecenazgo. A todos ellos, es común

2 Hasta que el título nobiliario pasa a la casa de Borbón en España con Isabel de Farnesio -segunda esposa de Felipe V- y con ello pasa a la corona española la fabulosa colección Farnesio, y el palacio Farnesio de Roma. El palacio fue vendido a Francia que instaló su embajada. La colección Farnesio, cuando Carlos VII rey de Nápoles y Sicilia, viene a España para convertirse en Carlos III - el mejor alcalde de Madrid- decide en un acto de respeto enorme al patrimonio cultural, dejar la colección Farnesio en Nápoles, porque era patrimonio cultural italiano. Además, dejó en el reino de Nápoles y Sicilia uno de los pilares fundamentales de la legislación de protección del patrimonio cultural, y el inicio de la legislación sobre excavación arqueológica, al haberse descubierto bajo su reinado Pompeya y Herculano. 
la cualidad de disponer de un importante patrimonio, exactamente igual que ocurrió en el mundo griego, en el romano, en la edad media, y en los periodos sucesivos hasta la actualidad. En contraste con ello, hoy día, muchos gobiernos, incluido el español, tienen como objetivo implicar al ciudadano de clase media en el mecenazgo, frente al pasado, cuando fueron las élites sociales y económicas, las que desarrollaron el mecenazgo. Un mecenazgo, que a veces desarrollaban conjuntamente la iglesia y la nobleza, colaborando con las cofradías, que a su vez realizaron un importante mecenazgo en el campo social con la asistencia a enfermos, huérfanos y desvalidos, y en el campo cultural financiando obras de arte3.

¿Qué causas o motivos impulsan el mecenazgo? Son varias las causas, y en función de la persona y sus circunstancias, confluyen en cada caso, con distinto peso:

1.1.1. El más admirable, es el mecenazgo, que tiene como única motivación el altruismo y la generosidad. Pero este mecenazgo es también el más escaso, lo que no quiere decir, que en todas las épocas podamos encontrar algunos ejemplos del mismo. Ejemplo histórico interesante de mecenazgo social, que sigue siendo noticia el 17 de diciembre de 20204, es la creación del Hospital de Nuestra Sra. De la Concepción y San Diego de Alcalá, en Medina del Campo. El mismo es conocido como Hospital Simón Ruiz. Un centro sanitario creado en la época en que Medina del Campo era el lugar de celebración de las ferias de comercio internacionales más importantes. Una época, en la que España tenía la exclusividad de la lana merina. La feria de lana merina era precisamente, una de las más importantes

3 Álvaro Vicente Hernández, Poseedores de Títulos e Grandezas: La Imagen de la Nobleza en los Territorios de Murcia. Tesis doctoral en acceso abierto en https://digitum.um.es/digitum/handle/ 10201/76901 acceso el 10 diciembre de 2019. 273.

$4 \mathrm{El} 17$ de diciembre de 2020 este Hospital fruto del mecenazgo privado se inaugura convertido por la Fundación Simón Ruiz en un centro de desarrollo económico y convirtiendo en un ejemplo de la sostenibilidad de la gestión, y del impacto social de las inversiones en la conservación del patrimonio y la necesidad de seguir impulsando la colaboración entre administraciones. La sinergia de colaboración puede llegar a dar estos frutos estupendos de mecenazgo social, cultural y de conservación del patrimonio cultural, pues parte de la rehabilitación se ha realizado con el 1,5\% cultural en concreto la Iglesia.

https://comunicacion.jcyl.es/web/jcyl/Comunicacion/es/Plantilla1ooDetalle/1284877983892/Nota Prensa/1285011984847/Comunicacion, acceso el 19 de noviembre de 2020. 
ferias que se celebraban en la localidad, aunque no la única. El comerciante Simón Ruiz, por puro altruismo, decidió dejar su gran patrimonio para la construcción de un hospital donde se curasen, "a todos los enfermos de todas las enfermedades". Al tratarse de disposición testamentaria, es evidentemente altruismo el motivo de este mecenazgo social. Hay muchos más, pero entiendo que un Hospital de más de seis mil metros cuadrados, que se construye en 1593, es un ejemplo significativo. El edificio se mantiene en pie, como testimonio histórico y artístico de primer nivel, y cuenta con el reconocimiento de B.I.C., por lo que goza de los beneficios fiscales, que la actual normativa concede. 5

1.1.2. No obstante, es más normal, que, aunque exista altruismo y generosidad, exista una motivación utilitarista. Lo más frecuente, es usar el mecenazgo como instrumento de distinción y promoción social o política. En este caso se incluyen además de la corona, la iglesia y la nobleza, a los ciudadanos enriquecidos o ascendidos a la nobleza con un oscuro pasado judeo-converso ${ }^{6}$.

La nobleza para engrandecer sus casas, aumentar su poder y su prestigio, una de las vías que utilizaba era hacerse patronos de conventos, y capillas mayores, poniendo sus escudos. Ello daba lugar a rivalidades entre las diferentes casas

5 Fernando, Campo del Pozo "Hospital y Fundación Simón Ruiz en Medina del Campo (Valladolid)" En La Iglesia española y las instituciones de caridad, coord. por Francisco Javier Campos y Fernández de (Sevilla: Real Centro Universitario Escorial-María Cristina: Ediciones Escurialenses, 2006), 499. Pascual Madoz, Diccionario geográfico-estadístico-histórico de España y sus, posesiones de ultramar (1845-1850)-Madoz, Pascual, 1806-1870 Facsímil de 1845-1850 Valladolid (1984) 83. https://bibliotecadigital.jcyl.es/i18n/consulta/resultados_navegacion.cmd?busq_autorobra=CYLA2 0090074910 \&descrip_autorobra=Obras\%20como\%20autor:\%20Madoz,\%20Pascual,\%2018061870 acceso el 13 diciembre de 2020. Esteban García Chico, Catalogo Monumental de la Provincia de Valladolid, Tomo IV. Partido Judicial de Medina del Campo, 1-19o (Valladolid, Editado por la Excma. Diputación de Valladolid, 1964), 163. Agustín Bustamante García, La arquitectura clasicista del foco vallisoletano (1541-1640), (Valladolid: Institución Cultural Simancas 1983),563.

6 Margarita Cabrera Sánchez, "El problema converso en Córdoba. El incidente de la Cruz del Rastro", en La Península Ibérica en la era de los Descubrimientos (1391-1492), Actas de las III Jornadas Hispano portuguesas de Historia Medieval, vol. I, (Sevilla, 1997), 335. De la misma autora "Los conversos de Córdoba en el siglo XV: la familia del jurado Martín Alfonso" en «Anuario de Estudios Medievales», 35 (2005), pp. 185-232. Ángel María Ruiz Gálvez, "Los estudios sobre el patrimonio judeoconverso en la corona de Castilla: las promociones artísticas como instrumento de integración social (ss. XV-XVII)". Mediterranean - recherché soroche - n. 46 Anno XVI - agosto 2019, pp. .220-250. Gonzalo j, Herreros Moya, "La reconstrucción del patrimonio judeoconverso. La familia, la casa y la capilla catedralicia de los Muñoz de Velasco en Córdoba”, "Historia y Genealogía», 8 (2018), 214 y s.s. 
nobles7. En algunos casos llegaban hasta el extremo de retirar una casa noble los escudos de los reyes, y colocar los suyos, acabando el enfrentamiento con muertes, y condenas de destierro. Es lo que sucedió en el convento de San Francisco de Cáceres ${ }^{8}$.

También las mujeres a lo largo de la historia, han tenido un protagonismo importante en el campo del mecenazgo, sobre todo social y religioso, aunque su visibilidad ha sido menor, salvo excepciones como María Dávila9. Esta mujer, que procedía de una familia de comerciantes abulenses, se encumbró con una magnífica relación con la reina Isabel, que promovió entre las mujeres de su época el mecenazgo espiritualio ${ }^{10}$ También es oportuno citar a Doña María de Guzmán, hija de Enrique de Guzmán, II Conde Niebla, y consorte del II Conde de Alba de Liste D. Enrique Enríquez de Mendoza, iniciadora de la construcción del magnífico convento de San Antonio de Garrovillas (Cáceres), un bien de interés cultural con un reconocimiento mundial, que sigue arruinándose. Ello, pese a las promesas, que su actual y única propietaria, la Junta de Extremadura, ha venido realizando.

\subsection{ANTECEDENTES PRÓXIMOS}

La actual regulación del mecenazgo, al igual que la normativa a la que sustituyó (Ley 30/1994, de 24 de noviembre, de Fundaciones y de incentivos fiscales a la participación privada en actividades de interés general) regulan unitariamente el mecenazgo social, cultural y deportivo. Ambas normas, en su preámbulo, ponen de relieve la necesidad de estimular la iniciativa privada en la

7 González Torrico, Antonio Jesús. "La Nobleza cordobesa y el patronazgo religioso". REVISTA DE ESTUDIOS DE CIENCIAS SOCIALES Y HUMANIDADES, núm. 30 (2013), 85.

8 María del Carmen Diez González, Arquitectura de los conventos franciscanos observantes en la provincia de Cáceres (s. XVI y s. XVII), Universidad de Extremadura, Cáceres 2003. Pág.169. Ricardo Hurtado de San Antonio, El Monasterio de San Francisco de Cáceres, Editorial El Brocense. Cáceres 1981, pág. 38.

9 María Dávila, mujer singular estuvo casada en primer lugar con el tesorero de los Reyes Católicos y luego con Fernando de Acuña, gobernador del reino de Galicia y virrey de Sicilia, que fue entre otras cosas, fundadora del monasterio de Clarisas de Ávila.

10 Cecilia Lagunas y Gonzalo Granara. "María de Ávila mujeres nobles, patrimonio y poder en el siglo XV” Magallánica: revista de historia moderna., N. ${ }^{\circ}$ 4, (2016), 157. 
realización de actividades de interés general. Una necesidad que se justifica, reconociendo en el preámbulo, que los poderes públicos no pueden atender plenamente todas las actividades de interés general, y también porque ya entonces se era consciente de que la sociedad demandaba, que el ámbito de las actuaciones altruistas tenía que estar estructurado jurídicamente de forma adecuada.

Los antecedentes legislativos próximos, que es oportuno citar, los dividimos en dos bloques, uno dedicado a las leyes publicadas, y otro, a los proyectos legislativos, que no han llegado a convertirse en leyes:

\subsubsection{Antecedentes legislativos:}

1.2.1.1. Los antecedentes legislativos más lejanos, van unidos al mecenazgo social, que es el mecenazgo prevalente en el siglo XIX y XX. En este sentido, la Gaceta de Madrid, publicaba el domingo 24 de junio de 1849, la regulación de la beneficencia en España a nivel nacional, provincial y municipal, distinguiendo la pública, de la realizada a través de Fundaciones particulares, financiadas por mecenas o filántropos. Este último, era el término más usual en el siglo XIX. De esta ley, nos parece oportuno destacar el artículo 17. Un precepto, que ha pervivido en el tiempo, hasta las actuales normativas de Fundaciones y Asociaciones. Dicho precepto disponía, que la supresión de cualquier entidad de beneficencia de fundación pública o privada, conllevaba la incorporación de sus bienes, rentas y derechos a otro establecimiento de igual condición. También es oportuno destacar, que esta Ley de 1849, es la primera, que reconoce las fundaciones de beneficencia ${ }^{11}$ particular, pese a la larga tradición existente en España, como ya hemos puesto de relieve con el Hospital Simón Ruiz del siglo XVI.

1.2.1.2. Real Decreto de 14 de mayo de 1852, que aprueba el Reglamento de la Ley General de Beneficencia, que supone la incardinación de las fundaciones en el campo del derecho administrativo.

11 Miguel A. Cabra de Luna "La regulación y funcionamiento de las fundaciones. Las fundaciones de titularidad pública. Especial referencia a las fundaciones públicas sanitarias”. Revista española de control externo, Vol. 3, N. ${ }^{\circ}$ 8, (2001), 29. 
1.2.1.3. Real Decreto e Instrucción de 14 de marzo de 1899 del régimen jurídico-público de las fundaciones asistenciales, puras y mixtas.

1.2.1.4. El Código Civil de 1889, que en el libro I, título II, dedica el capítulo II a regular las personas jurídicas. En su artículo 35 reconoció por primera vez como personas jurídicas de interés público, ${ }^{12}$ tanto a las Asociaciones, como a las Fundaciones, que adquieren personalidad jurídica una vez constituidas válidamente. A partir de esta norma, el interés público lo reconoce la ley, por tanto, tienen interés público las entidades comprendidas en el primer apartado del art. 35. También el mismo precepto reconoce las asociaciones de interés particular, que carecen por tanto de interés público y que pueden ser civiles, mercantiles o industriales. El Código Civil cierra este apartado en el art. 39, fijando para el supuesto de extinción de una corporación, asociación o fundación de interés público en cuanto a sus bienes. Estos artículos siguen vigentes sin modificación desde 1889 hasta la actualidad.

1.2.1.5. Real Decreto de 20 de julio de 1926, de instituciones y fundaciones benéfico-docentes particulares de enseñanza agrícola, pecuaria o minera, que reorganiza los servicios de beneficencia particular.

1.2.1.6. El Decreto 446/1961 de 16 de marzo de fundaciones laborales.

1.2.1.7. Decreto 2930/1972, de 21 de julio, por el que se aprueba el Reglamento de las Fundaciones Culturales Privadas y Entidades análogas, y de los Servicios administrativos, encargados del Protectorado sobre las mismas.

1.2.1.8. Ley $30 / 94$ de 24 de noviembre de Fundaciones y de incentivos fiscales a la participación privada en actividades de interés general. Es una ley fundamental, que vino a poner orden, unidad $^{13}$, coordinación y congruencia en un

12 José María Manresa y Navarro, Comentarios al Código Civil Español, Tomo I (1-709) de XII tomos, (Madrid: Editorial Reus ,1931), 215.

13 Isabel Peñalosa Esteban y Teresa Sanjurjo González, "La fiscalidad de las fundaciones: evolución, situación actual y perspectivas de futuro”, en La dimensión social de la fiscalidad: discapacidad, tercer sector y mecenazgo (Estudios en homenaje a Miguel Cruz Amorós), Dir. Por Miguel Ángel Cabra de Luna (Madrid: Editorial Cinca S.A., 2017), 198. 
sector, que tenía dispersa su normativa en normas pertenecientes a diferentes campos, y de diferentes rangos normativos.

1.2.1.9. La norma actualmente vigente, la ley $49 / 2002$ de 23 de diciembre. En los dieciocho años de vigencia, ha sufrido modificaciones importantes, como la introducida por la ley 62/2003, Además han sido múltiples los intentos y las promesas de sustituirla por una nueva ley, más acorde al momento histórico que vivimos.

1.2.1.10. Real Decreto 1270/2003 de 10 de octubre, por el que se aprueba el Reglamento para la aplicación del régimen fiscal de las entidades sin fines lucrativos y de los incentivos fiscales al mecenazgo.

1.2.2. Últimas propuestas de reforma del mecenazgo no llevadas a efecto:

1.2.2.1. Propuestas legislativas del Partido Socialista Obrero Español: En el año 2010 en su programa legislativo, como prioritario, incluyó una nueva Ley de Mecenazgo. Posteriormente en el programa electoral del año 2018, el Partido Socialista Obrero Español reitera entre sus objetivos: “Aprobar una nueva Ley de Mecenazgo y una serie de medidas fiscales y no fiscales para facilitar la participación de la sociedad civil en la financiación de la cultura, y el reconocimiento a los grandes y pequeños mecenas, permitiendo medidas simbólicas que resalten su valor ante la sociedad.”. En el mismo programa se afirma "Actualizaremos la regulación del patrocinio y el mecenazgo adaptándola a las nuevas necesidades del deporte. Se impulsará una verdadera y eficaz Ley de Patrocinio Deportivo que sirva de complemento a la financiación pública en los distintos ámbitos, estatal y autonómico".

1.2.2.2. Propuestas del Partido Popular en la IX legislatura: A su vez el Partido Popular presentó en el Congreso de los Diputados en la IX legislatura la proposición de ley 292-1 identificada como 122/000264, que no era una nueva ley de mecenazgo, sino una reforma parcial, pero importante de la ley 49/2002, Y lo era porque proponía cambios sustanciales, que por su interés sucintamente vamos a recoger: 
1.2.2.2.1. En el art. 16 incluía las Instituciones Culturales de la Administración General del Estado, que cumplan los correspondientes Códigos de Buenas Prácticas.

1.2.2.2. En el art. 17 incluía, la donación de bienes que formen parte del Patrimonio Mundial y elementos de Patrimonio Cultural Inmaterial reconocidos por la UNESCO, situados en España; así como el patrimonio tangible reconocido con el Premio Unión Europea de Patrimonio Cultural.

1.2.2.2.3. Elevaba el derecho a deducir de la cuota íntegra del Impuesto sobre la Renta de las Personas Físicas al 70 por 100 de la base de la deducción.

1.2.2.2.4. Elevaba el derecho a deducir en el Impuesto sobre Sociedades al 60 por ciento.

1.2.2.2.5. Se elevaba al 50 por ciento la deducción del importe de las inversiones o gastos realizados:

- en adquisición de bienes del Patrimonio Histórico Español fuera de España con determinadas condiciones.

- en conservación, reparación, restauración, difusión y exposición de bienes del Patrimonio Histórico Español.

- en rehabilitación de edificio, mantenimiento, reparación, infraestructuras etc. de bienes del Patrimonio Histórico Español y ciudades Patrimonio.

- Se elevaba al 20 por ciento de la base liquidable el límite de las anteriores deducciones.

- La misma reforma anterior se proponía para el Impuesto de Sociedades.

1.2.2.3. En la XII legislatura el Partido Popular vuelve a proponer una nueva Ley de promoción del mecenazgo, Núm. 332-1, como propuesta 122/o00292., en relación a la que acabamos de analizar del 2011 del mismo partido. Caben destacar como más notable las siguientes propuestas: 
1.2.2.3.1. La inclusión dentro de las actividades de mecenazgo de las donaciones de servicios, "pro bonos", y todo tipo de voluntariado que repercuta positivamente en el interés general.

1.2.2.3.2. La responsabilidad social corporativa.

1.2.2.3.3. La actividad específica de los objetivos de Desarrollo Sostenible 2030

1.2.2.3.4. La realización de seminarios, jornadas y otro tipo de formaciones que persigan fomentar la cultura del mecenazgo y sus fines de interés general.

1.2.2.3.5. Creación del Premio Nacional de Mecenazgo

1.2.2.3.6. Creación del día del Mecenazgo

1.2.2.3.7. Creación de la tarjeta de mecenas

1.2.2.3.8. Creación de un registro de mecenas

1.2.2.3.9. Creación de una estrategia nacional de mecenazgo

1.2.2.3.10. Creación de un Observatorio de Mecenazgo

1.2.2.3.11. Las deducciones de la cuota íntegra se fijan en el 80\%, para los primeros 150 euros, y 50\% para el resto. Con un límite del 20\% de la base liquidable, en el Impuesto sobre la Renta de las Personas Físicas.

1.2.2.3.12. Las deducciones en el Impuesto de Sociedades se fijan en el 60\%, con un incremento del 70\% por fidelización, y con el límite del 15\% de la base imponible.

1.2.2.3.13. Regulación específica para las donaciones a museos de titularidad estatal.

Curiosamente, ambos partidos políticos, pese a sus reiteradas promesas, cuando llegan al poder se limitan a hacer sólo cambios en los porcentajes. El partido popular, que gobierna con mayoría absoluta entre 2011 y 2018, no tramita su proyecto de mecenazgo, pero nada más irse a la oposición vuelve, como hemos visto, a presentar otra proposición de ley de Mecenazgo. Finalmente, el Partido 
Popular, a lo más que llega, después de múltiples y reiteradas promesas desde el Ministerio de Educación, Cultura y Deporte, presidido entonces por José Ignacio Wert, es a una reforma (publicada el 28 de noviembre de 2014) en vigor a partir del 29 de noviembre de 2014. Esta reforma puntual sólo modifica los porcentajes de deducción por mecenazgo del art. 19, 20 y 21 de la Ley 49/2002. Se elevan los porcentajes del artículo 19, hasta el $75 \%$ para los primeros ciento cincuenta euros. Y se añaden unos incrementos del 5\% por fidelización, tanto en el art. 19 para las personas físicas, como en el 20 para el Impuesto de Sociedades. Otra reforma que no se aprovechó para intentar resolver los múltiples problemas y defectos, que tiene la actual normativa de mecenazgo.

A su vez el Partido Socialista, que como hemos visto, llevaba en sus dos programas de Gobierno últimos, la reforma integral del Mecenazgo, realmente lo que hizo fue seguir los pasos del Partido Popular, limitándose a hacer una reforma mínima del mismo punto reformado por el Partido Popular. Esta mínima reforma no es otra cosa, que copiar una de las propuestas del proyecto de ley de mecenazgo del Partido Popular, que acabamos de analizar, o sea elevar el porcentaje del 75 por ciento al 80 por ciento. Esto se hace en pleno confinamiento por la pandemia con la norma publicada el 6 de mayo de 2020, con entrada en vigor el 7 de mayo de 2020.

Parece claro, que las proposiciones de Ley y las promesas electorales, que se presentan por los partidos políticos, cuando no están en el poder, son muy generosas en incentivos fiscales. Son actos de campaña, recordando la famosa frase atribuida a Tierno Galván "las promesas electorales están para no cumplirse”.

1.2.2.4. Por último, hay otros proyectos de ley, que tampoco salen adelante: el presentado por el Grupo Parlamentario Catalán (Convergència y Unió) núm. 183 de 23 de mayo de 2014; y la Proposición de Ley presentada por el Grupo parlamentario Ciudadanos, de fomento y reconocimiento del Mecenazgo, Micro mecenazgo y Voluntariado núm. 334, publicado el 2 de noviembre de 2018, con el núm. 3 . 
Considero oportuno resaltar de estos proyectos (Proposición de Ley de Ciudadanos y Proposición de Ley de Convergencia y Unió), dos de los puntos más interesantes, que siguen sin desarrollarse a nivel estatal, en la actualidad.

Ambos admiten como formas de mecenazgo las prestaciones de servicios.

Ambos proyectos contemplan la deducción del 100\% sobre los primeros 150 euros en el Impuesto sobre la Renta de las Personas Físicas y el 50 o 55 por ciento para el resto en el Impuesto de Sociedades.

1.2.2.5. Leyes de Mecenazgo de las Comunidades Autónomas.

Y para terminar este apartado indicar que, junto a la normativa estatal de mecenazgo, las Comunidades Autónomas han empezado a desarrollar su normativa propia, con bastante más éxito, que la normativa estatal:

1.2.2.5.1 La Ley Foral 8/2014, de 16 de mayo. Reguladora del Mecenazgo Cultural y de sus incentivos fiscales en la Comunidad Foral de Navarra.

1.2.2.5.2 La ley 9/2014 de la Comunidad Valenciana, que ha sido sustituida por la Ley 20/2018, de 25 de julio, de la Generalitat, del mecenazgo cultural, científico y deportivo no profesional en la Comunitat Valenciana.

1.2.2.5.3 Norma Foral 4/2019, de 20 de marzo, de Régimen Fiscal de las Entidades sin fines lucrativos y de los Incentivos Fiscales al Mecenazgo. (BOB 4 abril) del País Vasco.

1.2.2.5.4 Ley 3/2015, de 23 de marzo, por la que se regula el consumo cultural y el mecenazgo cultural, científico y de desarrollo tecnológico, y se establecen medidas tributarias de las Islas Baleares.

1.2.2.5.5 Ley 9/2019, de 13 de diciembre, de Mecenazgo Cultural de CastillaLa Mancha.

Normativas más actuales, más eficientes y más eficaces que la estatal.

Con todo ello, el mapa del mecenazgo en España es un mapa asimétrico, difícil de comprender para alguien no versado en el complejo campo de competencias estatales y autonómicas en España. A ello se une otro aspecto más 
complejo, y es la distinción entre comunidades autónomas de régimen común y comunidades autónomas que tienen un régimen tributario propio, o sea el sistema de concierto y convenio económico que sigue vigente en la actualidad y que deja fuera de la ley 49/2002 a Navarra y el País Vasco. En el resto de Comunidades Autónomas la normativa estatal regula lo referente a los impuestos estatales, gestionados por el Estado, y las Comunidades autónomas los impuestos propios, y cedidos, con los tramos autonómicos del I.R.P.F. En conjunto una selva legislativa, solo para avezados en el derecho fiscal, que crea situaciones muy diferentes a lo largo y ancho del territorio español.

\section{LOS FINES DE INTERÉS GENERAL Y LA JUSTIFICACIÓN DE LOS BENEFICIOS FISCALES POR DESARROLLAR ACTIVIDADES DE INTERÉS GENERAL14}

La conexión del mecenazgo y los fines de interés general es directa en la legislación vigente, en cuento se entiende que el mecenazgo consiste en la participación privada en la realización de actividades de interés general.

Pero ¿Qué es el interés general? La Constitución Española en su artículo 103 dispone "La Administración pública sirve con objetividad los intereses generales con sometimiento pleno a la Ley al Derecho”. ¿Es igual interés general, que interés público? En principio sí.

La expresión “interés general" se emplea hasta doce veces en la Constitución: artículos 30.2 "Podrá establecerse un servicio civil para el cumplimiento de fines de interés general”, y artículo 34.1. "Se reconoce el derecho de fundación para fines de interés general, con arreglo a la ley”. Art. 44.2, 47, 128 apartados 1 y 2, 149 apartados 20 y 24, 150, 155 .

No obstante la reiterada utilización de la expresión interés general, el legislador rehúye dar un concepto de fines de interés general, y en sustitución de

14 Esteban Palacios Ronda, "Utilidad pública de las asociaciones. Revocación por la Administración y solución fundacional”, REVESCO: revista de estudios cooperativos, № . 130, (2019), 118. 
ello da un número ejemplificativo de fines, que no es más que un númerus apertus, como queda claro en el art. 3.1 ${ }^{\circ}$ de la Ley 49/2002 donde se afirma son " fines de interés general,... entre otros, los de defensa de los derechos humanos, de las víctimas del terrorismo y actos violentos, los de asistencia social e inclusión social, cívicos, educativos, culturales, científicos, deportivos, sanitarios, laborales, de fortalecimiento institucional, de cooperación para el desarrollo, de promoción del voluntariado, de promoción de la acción social, defensa del medio ambiente, de promoción y atención a las personas en riesgo de exclusión por razones físicas, económicas o culturales, de promoción de los valores constitucionales y defensa de los principios democráticos, de fomento de la tolerancia, de fomento de la economía social, de desarrollo de la sociedad de la información, de investigación científica, desarrollo o innovación tecnológica y de transferencia de la misma hacia el tejido productivo como elemento impulsor de la productividad y competitividad empresarial."

En consecuencia, puede haber fines de interés general que no estén en este apartado, y a la vez cuando una entidad se dedica en parte a fines que no pueden calificarse como de interés general, quedan excluidos del precepto ${ }^{15}$.

El concepto de "fines de interés general" y su correlativo "actividades de interés general", son conceptos jurídicos indeterminados, y con un carácter expansivo, pues la evolución legislativa no deja de incrementar los fines y las actividades de interés general.

Fines de interés general, son los contrarios a fines de colectivos específicos, concretos y particulares. Pero como concepto jurídico indeterminado exige un

15 La Consulta vinculante Vo939-15 de fecha 25/03/2015 analizando los arts. 3,6,7 y s.s. de la Ley 49/2002 analiza la posibilidad de calificar como fin de interés general una actividad no incluido en el número de fines recogido en el art. $3 \cdot 1^{\circ}$. La Fundación tiene como objeto social la promoción y difusión de una serie de fiestas regionales, que se celebran anualmente en honor de su patrón. Se rechaza porque "En efecto, los fines perseguidos por la entidad relativos a la promoción y difusión de la Fiesta Mayor de Villafranca del Penedés, tiene difícil encaje para considerar dicha actividad como de interés general, en la medida en que se destina a una colectividad determinada de beneficiarios y no puede encuadrarse en ninguno de los fines previstos en el artículo 3 de la Ley 49/2002, de 23 de diciembre, anteriormente reproducido." 
análisis individualizado en todas las situaciones no recogidas en el art. $3 \cdot 1^{\circ}$ de la Ley 49/2002.

Los entes públicos tienen que desarrollar actividades destinadas a cumplir fines de interés general, frente al interés particular o individual. Por lo que cuando la sociedad civil, por altruismo y generosidad realiza actividades de interés general, no hace otra cosa que sustituir y ahorrar recursos a los entes públicos. Me parece conveniente resaltar este aspecto, dado que hay sectores, que sostienen, que el que quiera ser generoso que lo sea, pero no tiene que disfrutar beneficio fiscal alguno. A mi criterio, los beneficios fiscales, encuentran uno de los sentidos más lógico en situaciones en que el ciudadano sustituye a los entes públicos, en la realización de actividades de interés general ${ }^{16}$. Si se trata de actividades que no son de interés general, yo también estoy de acuerdo que no tiene sentido un beneficio fiscal. El tercer sector formado por fundaciones y asociaciones que tienen como objeto desarrollar fines de interés general, sirven al bien común, al realizar fines de interés público.

Cuando los políticos, en sus cargos públicos deciden como gastar el dinero público están realizando, en principio, actividades públicas de interés general. Cuando un ciudadano, al margen de su ideología política, hace mecenazgo para contribuir en el desarrollo de una actividad de interés general, está decidiendo directamente en que se gasta no sólo el dinero que aún conserva en su poder, después de pagar impuestos. Está eligiendo sus preferencias de forma directa y no a través de los políticos. Que se concedan beneficios fiscales es de absoluta justicia y equidad, bastante más justicia y equidad que el dinero donado a los partidos

16 Pietro Boria, "Il sistema tributario", En Diritto Tributario, a cura di Augusto Fantozzi, IV edizione, (Torino, UTET, 2012): 18., María Teresa Querol García, "Régimen fiscal de las entidades sin fines de lucro y de los incentivos fiscales al mecenazgo". Carta Tributaria - Monografías, No 3, Sección Monografías, (Quincena del 1 al 15 Feb. 2008): 8. Alejo Hernández Lavado, "El paisaje como patrimonio cultural y su protección en España a través de los tributos”. En. La Cultura del restauro e della valorizzazione. Temi e problema per un percorso internazionale di conoscenza. Dir. Bertocci, S y Van Riel S., (Firenze. Altralinea edizioni s.r.l.2014), 1205.

16 María del M. Soto Moya, "Incentivos fiscales al micromecenazgo digital como fórmula de colaboración social "en Fiscalidad de la Colaboración Social. Coordinada por Pedreira Menéndez, J. y Pascual González, (Pamplona. Editorial Aranzadi, S.A.U.,2018), 52. Carmen Márquez Sillero, La exención de las Fundaciones en el Impuesto sobre Sociedades. Conforme a la Ley 49/2002”, edición $\mathrm{n}^{\mathrm{O}}$ 1, (Madrid: Editorial LA LEY, Madrid, mayo 2007), 107. 
políticos para gastar en actividades que no son de interés general, sino de interés particular del partido político.

Un partido político es un cauce de actuación, distinto, y diferente al de la sociedad civil, legal y legítimamente legalizada y organizada. En las entidades del tercer sector, la ideología o pertenencia a un partido político es una cuestión privada. Aunque es cierto, que en la praxis los partidos políticos buscan y muchas veces consiguen controlar, y manejar para sus propios intereses las entidades del tercer sector. Una corruptela altamente perjudicial para la sociedad.

Por último, indicar, lo llamativo que resulta, que determinados políticos sigan poniendo objeciones a los beneficios fiscales en las donaciones a las entidades no lucrativas, que desarrollan actividades de interés general, pero no pongan las mismas objeciones a las donaciones a partidos políticos que lucran beneficios fiscales. Y ello teniendo en cuenta la historia de corrupción, que las donaciones a partidos políticos tienen dentro y fuera de España.

\section{DEDUCCIONES A QUE DAN DERECHO LAS ACTIVIDADES DE INTERÉS GENERAL FINANCIADAS CON APORTACIONES DE LA SOCIEDAD CIVIL}

La situación actual parte de la reforma operada en la ley 49/2002 por la ley 14/2014 del Impuesto de Sociedades, que empezó a aplicarse el 1 de enero de 2015 en parte, y de forma total el 1 de enero de 2016. Esta reforma que incide esencialmente en los beneficios fiscales que se conceden a los donantes, ha beneficiado a unas entidades no lucrativas y ha perjudicado y agravado la situación de otras muchas entidades no lucrativas. Con esta reforma del mecenazgo en general, que se concreta en modificar los artículos 19, 20 y 21 de la Ley 49/2002 se pretendió incrementar el micro mecenazgo de particulares. La reforma, como ya hemos indicado, consistió en la introducción de unos elevados incentivos fiscales a donaciones inferiores o iguales a 150 euros. La reforma ha tenido un impacto positivo en las fundaciones y en las entidades no lucrativas declaradas de utilidad pública, que han visto incrementadas las donaciones, pero 
no en las entidades que han visto su situación jurídica cambiada, al ser asociaciones no declaradas de utilidad pública.

A ello, tenemos que unir, que la legislación mercantil, administrativa y tributaria es totalmente inadecuada. Inadecuada para los grandes mecenas, inadecuada para el mecenazgo en general, y destructora de muchas entidades no lucrativas, que trabajan realizando desde la gratuidad actividades de interés general, que los entes públicos no tienen capacidad, ni medios para desarrollar. La normativa que hoy se aplica a las entidades no lucrativas, especialmente el Impuesto de Sociedades desde el ejercicio del año 2015, está pensada para el mundo empresarial, para las entidades que tienen como objeto ganar dinero. Es un problema generado por la configuración del hecho imponible del Impuesto de Sociedades, que se centra en la renta obtenida por las personas jurídicas, sin consideración al origen ni el destino de la renta, lo que viene siendo criticado por la doctrina ${ }^{17}$. Además, las obligaciones formales y de todo tipo asfixian al sector no lucrativo. Algunas entidades ven mermados, de forma importante sus recursos, que son las aportaciones generosas de sus asociados, que no pueden desgravar dichas aportaciones, o si lo hacen no pueden recibir ninguna contraprestación de carácter simbólico de la entidad, como es normal y habitual en los países desarrollados. Las obligaciones formales, que se exigen a las entidades no lucrativas, obligan a contratar personal especializado dedicado a las gestiones con la Agencia Tributaria. Ello consume una parte fundamental de los recursos. Cualquier error administrativo simple genera quedar fuera de las subvenciones, impidiendo el desarrollo de proyectos gratuitos en actividades de interés general, de gran valor para la sociedad.

17 Carmen Márquez Sillero, La exención de las fundaciones..., 147 y s.s. 
Como también hemos mencionado, se ha producido otra reforma por el Real Decreto-ley 17/2020, de 5 de mayo que ha incrementado del $75 \%$ al $80 \%$. Con ésta última reforma el mapa de los incentivos fiscales al mecenazgo aplicables desde el 1 de enero de 2020, queda así:

\begin{tabular}{|l|l|l|l|}
\hline $\begin{array}{l}\text { Impuesto Renta de } \\
\text { Personas Físicas }\end{array}$ & GENERAL & $\begin{array}{l}\text { Hasta } 150 \text { euros: } 80 \% \\
\text { Resto 35\% }\end{array}$ & $\begin{array}{l}+5 \% \text { en el caso de que la actividad este } \\
\text { declarada prioritaria }\end{array}$ \\
\hline $\begin{array}{l}\text { Impuesto Renta de } \\
\text { Personas Físicas }\end{array}$ & FIDELIZADO & $\begin{array}{l}\text { Hasta } 150 \text { euros: } 80 \% \\
\text { Resto: } 40 \%\end{array}$ & $\begin{array}{l}+5 \% \text { en el caso de que la actividad este } \\
\text { declarada prioritaria }\end{array}$ \\
\hline $\begin{array}{l}\text { Impuesto } \\
\text { Sociedades }\end{array}$ & GENERAL & $35 \%$ & $\begin{array}{l}+5 \% \text { en el caso de que la actividad este } \\
\text { declarada prioritaria }\end{array}$ \\
\hline $\begin{array}{l}\text { Impuesto de } \\
\text { Sociedades }\end{array}$ & FIDELIZADO & $40 \%$ & $\begin{array}{l}+5 \% \text { en el caso de que la actividad este } \\
\text { declarada prioritaria }\end{array}$ \\
\hline
\end{tabular}

En el cuadro no hemos distinguido entre el Impuesto sobre la Renta de las Personas Físicas residentes y no residentes.

A su vez la reforma de mayo de 2020, no ha modificado los porcentajes del mecenazgo en el Impuesto de Sociedades que sigue siendo el 35\%, y pasa al 40\% por fidelización, para los donantes que en los dos ejercicios anteriores han realizado donativos, donaciones o aportaciones, con derecho a deducción por importe igual o superior, en cada uno de ellos al del periodo anterior.

Como se aprecia en el cuadro, cuando una actividad de mecenazgo es calificada como prioritaria en la ley de Presupuestos Generales del Estado, tiene derecho a un incremento en la deducción del $5 \%$ con carácter adicional. Las actividades prioritarias de mecenazgo de los Presupuestos Generales del Estado del año 2018, fueron prorrogadas para el 2019, y luego lo han sido para 2020. 
3.1. LÍMITES Y PROBLEMAS QUE GENERA LA APLICACIÓN DE LOS PORCENTAJES DE DEDUCCIÓN

Es fundamental tener en cuenta, que estos porcentajes, se aplican al total de donaciones efectuadas por un contribuyente y que tienen como límite el diez por ciento de su base liquidable en el Impuesto sobre la Renta de las Personas Físicas, y el diez por ciento de la base imponible del Impuesto de Sociedades ${ }^{18}$. La diferencia entre base imponible y liquidable en el Impuesto sobre la Renta de las Personas físicas se encuentra en unas reducciones concretas ${ }^{19}$.

La Ley da un tratamiento más perjudicial a las personas físicas, consistente en que el límite del 10 por ciento implica, que por la cantidad donada que exceda de dicho límite, la persona física pierde el derecho a deducción. Esta situación provoca una limitación importante en las donaciones de personas físicas de cierta cuantía, bien dineraria o del valor del bien. Es especialmente gravoso en las donaciones para constituir una Fundación. La cantidad mínima para constituir una Fundación es 30.000 euros. Un fundador que quiera ser fundador, o bien tiene una base liquidable de 300.000 euros, o en caso contrario pierde la deducción.

En contraposición a lo anterior, si la donación la hace una sociedad, lo que la sociedad no pueda deducir un año, lo deduce en los diez años siguientes. Esta norma, provoca en la práctica, que, en la constitución de Fundaciones, con aportación del fundador, se tienda a realizar desde sociedades propiedad del

18 La base imponible que está sujeta al Impuesto estará constituida por el resultado contable del ejercicio económico ajustado por la corrección de ingresos que no son imputables fiscalmente y gastos que no son deducibles fiscalmente, obteniendo una base ajustada que se minora por las bases imponibles negativas de años anteriores. Art. 10 de la Ley del Impuesto sobre Sociedades.

19 De conformidad con el Artículo 50 del Impuesto sobre la Renta de las Personas Físicas "1. La base liquidable general estará constituida por el resultado de practicar en la base imponible general, exclusivamente y por este orden, las reducciones a que se refieren los artículos 51(Reducciones por atención a situaciones de dependencia y envejecimiento), 53(Reducciones por aportaciones y contribuciones a sistemas de previsión social constituidos a favor de personas con discapacidad.), 54 (Reducciones por aportaciones a patrimonios protegidos de las personas con discapacidad), 55(Reducciones por pensiones compensatorias) y disposición adicional undécima de esta Ley, sin que pueda resultar negativa como consecuencia de dichas disminuciones.2. La base liquidable del ahorro será el resultado de disminuir la base imponible del ahorro en el remanente, si lo hubiera, de la reducción prevista en el artículo 55(Reducciones por pensiones compensatorias), sin que pueda resultar negativa como consecuencia de tal disminución. 
fundador ${ }^{20}$, lo que no deja de ser una corruptela provocada por una discriminación creada por el propio legislador.

Las consecuencias son claras. Mientras de los fondos donados en Europa en el año 2017, el Reino Unido realizó el 25\%, Alemania el 23,8\%, Italia el 9,1\% y Francia el 8,4\%. España llegó al 3,7\%. ${ }^{21} \mathrm{Si}$ encima tenemos en cuenta que el 70\% de las donaciones la realizan las sociedades ${ }^{22}$, es difícil comprender la satisfacción que desde el Ministerio de Cultura se tiene con el funcionamiento del Mecenazgo. No olvidemos que en el año 2017 ya llevaba desde 2014 en vigor la reforma, que estableció nada menos que un $75 \%$ para los primeros 150 euros. Ello confirma lo que he defendido en varias ocasiones, que no es cuestión de establecer un gran porcentaje, sino de una reforma integral del Mecenazgo. Por ello, el haberse subido en pleno confinamiento del $75 \%$ al $80 \%$ el porcentaje de deducción, no es más que Ad pompam vel ostentationem, o como decimos los abogados, al realizar un informe forense con la presencia del cliente, "hablar para la galería".

Apoyo mis afirmaciones anteriores con las siguientes tablas de elaboración propia, para analizar cuantitativamente la evolución de las donaciones y el impacto en el número de donantes, y cuantía de las donaciones, que han producido las reformas que incrementan los beneficios fiscales.

20 Esteban Palacios Ronda, "Utilidad Pública...,120.

21 Datos obtenidos de la Asociación Española de Fundraising.

22 En Italia el mecenazgo empresarial ha tenido un desarrollo espectacular a través del programa público "Arts Bonus”. Marco Cammelli, “Attività e beni culturali: interventi, regimi e problema. Il ruolo delle fondaziones bancarie nelle attività" en Forme private e interessi generali quale ruolo per le fondazioni?: atti del XVIII Congresso dell'Associazione Italo-Spagnola dei Professori di Diritto Ammnistrativo, Bologna, 27-29 maggio 2010. Autores: Fabio A. Roversi Monaco (coord.), Marco Cammelli (coord.), Luciano Vandelli (coord.) Editores: Bolonia University Press Italia 2012. Pág, 111. 22 Magnani, Marco. Sette anni di vacche sobrie. Come sarà del 2020; Sfide e opportunità dicrescita per sopravvivera alla crisi. Con la collaborazione di Angel Ciancarella. Editorial UTET. Milano 2012 


\begin{tabular}{|c|c|c|c|c|c|c|c|}
\hline 1.I.R.P.F. & 2.Declarantes & 3Número donantes & 4. Importe donación & $\begin{array}{l}\text { 5.Media de la } \\
\text { donación }\end{array}$ & $\begin{array}{l}\text { 6.Donante de } \\
\text { A.P.M. }\end{array}$ & 7.Importe donación & $\begin{array}{l}\text { 8.media de la } \\
\text { donación }\end{array}$ \\
\hline $2010 \mathrm{E}$ & 19.257 .120 & 2.521 .097 & 94.827 .847 & 37,61 & & & \\
\hline $2010 \mathrm{~A}$ & 19.257 .120 & No hay & desglose & & & & \\
\hline $2011 \mathrm{E}$ & 19.467 .730 & 2.609 .621 & 98.897 .017 & 37,90 & & & \\
\hline $2011 \mathrm{~A}$ & 19.467 .730 & 2.609 .373 & 98.891 .120 & 37,90 & & & \\
\hline $2012 \mathrm{E}$ & 19.379 .484 & 2.914 .253 & 102.067 .533 & 35,02 & & & \\
\hline $2012 \mathrm{~A}$ & 19.379 .484 & 2.914 .005 & 102.060 .320 & 35,02 & & & \\
\hline $2013 \mathrm{E}$ & 19.203 .136 & 2.819 .352 & 105.854 .384 & 37,55 & & & \\
\hline $2013 \mathrm{~A}$ & 19.203 .136 & 2.818 .595 & 105.847 .994 & 37,55 & & & \\
\hline $2014 \mathrm{E}$ & 19.359 .020 & 2.946 .889 & 110.748 .958 & 37,58 & & & \\
\hline $2014 \mathrm{~A}$ & 19.359 .020 & 2.946 .032 & 110.742 .067 & 37,59 & & & \\
\hline $2015 \mathrm{E}$ & 19.480 .560 & 3.035 .784 & \begin{tabular}{|l|}
170.791 .827 \\
\end{tabular} & 56,26 & & & \\
\hline $2015 \mathrm{~A}$ & 19.480 .560 & 3.035 .740 & 170.781 .542 & 56,26 & & & \\
\hline 2016 & 19.621 .728 & 3.096 .245 & 496.476 .306 & 152 & 41.289 & 5.479 .788 & 133 \\
\hline 2017 & 19.913 .239 & 3.353 .866 & 506.623 .613 & 151 & 30.447 & \begin{tabular}{l|l|}
4.431 .557 \\
\end{tabular} & 146 \\
\hline 2018 & 20.608 .731 & 3.498 .324 & 528.912 .129 & 151 & 33.291 & \begin{tabular}{|l|}
4.667 .694 \\
\end{tabular} & 140 \\
\hline
\end{tabular}

Tabla 1. Elaboracion propia a partir de los datos de la agencia tributaria del Impuesto sobre la Renta de las Personas Físicas

1.Año

2.Núm. total de declarantes en el Impuesto sobre la Renta de las Personas Físicas.

3.Núm. de personas declarante en IRPF con donativos a entidades reguladas en ley 49/2002.

4.Importe de las cantidades totales por año declaradas donadas.

5.Importe medio de la donación persona/año.

6.Núm. de personas declarantes en actividades prioritarias de mecenazgo.

7.Importe total de las donaciones con destino actividades prioritarias de mecenazgo.

8. Importe medio de la donación persona año en actividad prioritaria de mecenazgo.

\subsection{ESTRUCTURA DE LA TABLA.}

La tabla tiene una estructura que varía en función de la variación en el desglose de los datos, que la Agencia Tributaria realiza en su sección de estadística, de tal forma: 
1.- Que no hemos querido seguir en años anteriores al 2010, aunque hubiera sido interesante contrastar datos de antes y después del año 2003, en que entra en vigor la ley 49/2002, porque no se desglosan los datos de deducciones autonómicas en 2010 y anteriores.

2.-Tampoco tenemos desglose de deducciones separadas en actividades prioritarias de mecenazgo en el ejercicio $2015 \mathrm{y}$ anteriores.

3.- Los datos hasta el ejercicio de 2015 aparecen desglosados a nivel estatal y autonómico. y no hemos considerado oportuno intentar unificarlos, pues no somos expertos en estadística. Lo hemos llevado a cabo, extrayéndolos de lo que tiene publicado la Agencia Tributaria en su sección de estadística.

El objetivo del cuadro, es reflejar la evolución en los donativos realizados a entidades no lucrativos acogidos a la ley 49/2002. E independientemente que cada cual puede sacar sus propias conclusiones, entiendo que se puede afirmar, que comparando los datos anteriores a la reforma de 2014 y posteriores no se observa que el incremento sea espectacular. Es más, tenemos años anteriores a la reforma que el incremento de donantes es superior a después de la reforma. Cierto que hay una línea ascendente de donantes e importe de donaciones, pero tengamos en cuenta que ello guarda una proporción con el incremento de la población y con el incremento de declarantes. Además, todo apunta a que el incremento se está produciendo en entidades de carácter socio-sanitario y no cultural que se están viendo perjudicadas. Para demostrar mejor mi postura, he realizado una segunda tabla añadiendo columnas con el incremento de declarantes, incremento de donantes e incremento de donaciones.

Hemos esperado hasta abril, para ver si la Agencia Tributaria colgaba los datos correspondientes a 2019, pero hemos tenido que cerrar el artículo sin poderlos llevar a cabo. Será interesante saber el incremento en el número de donantes y la media de cantidad donada en el 2019, en el 2020 preveo que el micro mecenazgo baja y sólo resiste el gran mecenazgo. De momento lo que tenemos claro es que en el 2017 se incrementó el número de donantes en el Impuesto sobre la Renta de las Personas Físicas en 257621 personas, si bien en el 2016 la cantidad media donada fue de 152 euros y en el 2017 lo fue de 151. Por otra parte, en el 2018 el incremento 
de donantes se reduce a 144.458 y la media de cantidad donada permanece en 151 euros. Esto, reafirma que el incremento en las donaciones está relacionado esencialmente con el incremento en el número de declarantes de la segunda columna de la siguiente tabla. Y que lo progresión no es ascendente. Quedamos a la espera de los datos de 2019 y 2020 y considero van a ser muy significativos.

\begin{tabular}{c|l|l|l|l|l|l|l} 
I.R.P.F. & Declarantes & $\begin{array}{l}\text { Incremento } \\
\mathrm{N}^{\circ} \\
\text { declarantes }\end{array}$ & $\begin{array}{l}\text { Número } \\
\text { Donantes }\end{array}$ & $\begin{array}{l}\text { Incremento } \\
\text { de } \\
\text { donantes }\end{array}$ & $\begin{array}{l}\text { Importe } \\
\text { donación }\end{array}$ & $\begin{array}{l}\text { Incremento } \\
\text { donación }\end{array}$ & $\begin{array}{l}\text { de } \\
\text { donació } \\
\mathbf{n}\end{array}$ \\
\hline $2010 \mathrm{E}$ & 19.257 .120 & & 2.521 .097 & & 94.827 .847 & & 37,61 \\
\hline $2010 \mathrm{~A}$ & 19.257 .120 & & No hay & & desglose & & \\
\hline $2011 \mathrm{E}$ & 19.467 .730 & 210.210 & 2.609 .621 & 88.524 & 98.897 .017 & 4.069 .170 & 37,9 \\
\hline $2011 \mathrm{~A}$ & 19.467 .730 & & 2.609 .373 & & 98.891 .120 & & 37,9 \\
\hline $2012 \mathrm{E}$ & 19.379 .484 & -87.846 & 2.914 .253 & 304.632 & 102.067 .533 & 3.170 .516 & 35,02 \\
\hline $2012 \mathrm{~A}$ & 19.379 .484 & & 2.914 .005 & & 102.060 .320 & 3.169 .200 & 35,02 \\
\hline $2013 \mathrm{E}$ & 19.203 .136 & -176.348 & 2.819 .352 & -94.901 & 105.854 .384 & 3.786 .851 & 37,55 \\
\hline $2013 \mathrm{~A}$ & 19.203 .136 & & 2.818 .595 & & 105.847 .994 & 3.787 .674 & 37,55 \\
\hline $2014 \mathrm{E}$ & 19.359 .020 & 155.884 & 2.946 .889 & 127.537 & 110.748 .958 & 4.895 .574 & 37,58 \\
\hline $2014 \mathrm{~A}$ & 19.359 .020 & & 2.946 .032 & & 110.742 .067 & 4.894 .073 & 37,59 \\
\hline $2015 \mathrm{E}$ & 19.480 .560 & 121.540 & 3.035 .784 & 88.895 & 170.791 .827 & 60.042 .869 & 56,26 \\
\hline $2015 \mathrm{~A}$ & 19.480 .560 & & 3.035 .740 & & 170.781 .542 & 60.039 .475 & 56,26 \\
\hline 2016 & 19.621 .728 & 141.168 & 3.096 .245 & 60.461 & 496.476 .306 & 154.902 .937 & 152 \\
\hline 2017 & 19.913 .239 & 291.511 & 3.353 .866 & 257.621 & 506.623 .613 & 10.147 .307 & 151 \\
\hline & 20.608 .731 & 695.492 & 3.498 .324 & 144.458 & 528.912 .129 & 22.288 .516 & 151 \\
\hline
\end{tabular}

Tabla 2 Elaboración propia para obtener la comparativa de incrementos y decrementos por año, en el número de declarantes, donantes e importe de las donaciones

\section{DONACIONES CON DERECHO A DEDUCCIÓN}

El artículo 17 comienza exigiendo que los donativos, donaciones y aportaciones reúnan una serie de condiciones. 
4.1. LAS CONDICIONES, QUE HAN DE REUNIR LAS DEDUCCIONES PARA TENER DERECHO A LA DEDUCCIÓN POR MECENAZGO SON:

4.1.1. Tienen que ser irrevocables. Si bien en el mismo artículo 17 apartado 2 se aclara, "En el caso de revocación de la donación por alguno de los supuestos contemplados en el Código Civil, el donante ingresará, en el período impositivo en el que dicha revocación se produzca, las cuotas correspondientes a las deducciones aplicadas, sin perjuicio de los intereses de demora que procedan. Por lo que una cosa es la revocación por voluntad del donante, que esta vetada, y otra, por imperativo legal que está admitida. Las causas legales de revocación de la donación, vienen reguladas en el Capítulo IV que lleva por rúbrica, "De la revocación y reducción de las donaciones" del Título II, del Libro tercero del Código Civil (Art. 644-656, Código Civil).

Lo establecido en el párrafo anterior se aplicará en los supuestos a los que se refiere el apartado 2 del artículo 23 de la Ley Orgánica 1/2002, de 22 de marzo, reguladora del Derecho de Asociación.”.

4.1.2. Tienen que ser puras.

4.1.3. Tienen que ser simples.

Hay una falta de flexibilidad en estos exigentes requisitos, que origina importantes dificultades, sobre todo en las donaciones cuantiosas de bienes y derechos.

En cuanto a la materialización de las donaciones con derecho a deducción, tenemos conforme a la normativa vigente, las siguientes opciones.

\subsection{ELENCO DE BIENES Y DERECHOS QUE PUEDEN SER DONADOS:}

4.2.1. El primero y menos conflictivo es el dinero.

4.2.2. Bienes muebles e inmuebles.

4.2.3. Derechos. 
4.2.4. Las Cuotas de afiliación a asociaciones. Ahora bien, con una condición que hace en la práctica, sea francamente difícil, que una cuota de una asociación pueda dar derecho a deducción. El legislador ha puesto la condición, que el pagar una cuota, no puede al asociado generarle el derecho a percibir una prestación presente o futura. En el mundo actual, no se entiende la captación de asociados sin ofrecer recompensas simbólicas. El criterio del legislador español hace un daño enorme al desarrollo del Mecenazgo, que está dificultando gravemente su desarrollo. En múltiples países es norma habitual, que el asociado desgrave sus cuotas, aunque tenga contraprestaciones simbólicas, en Francia alcanzan el 25\%. En la praxis, en España vivimos una situación esquizofrénica. Si consultas fundaciones, y asociaciones culturales de todo tipo y de todo nivel, lo normal es, por una parte, que pongan de manifiesto al asociado, entregándole el correspondiente certificado, que su donación es deducible en el Impuesto sobre la Renta de las Personas Físicas, y a la vez se le oferten privilegios y contraprestaciones de escaso valor, como incentivos para que se asocien. Ello con el estricto criterio de la Agencia Tributaria es imposible, pero no me consta, de lo cual me alegro, que la Agencia Tributaria lo esté inspeccionando y exigiendo. Y es que a veces el sentido común se superpone a la legalidad.

4.2.5. La constitución de un derecho real de usufructo sobre bienes, derechos o valores, realizada sin contraprestación.

4.2.6. Donativos o donaciones de bienes que formen parte del Patrimonio Histórico Español, que estén inscritos en el Registro general de bienes de interés cultural, o incluidos en el Inventario general a que se refiere la Ley 16/1985, de 25 de junio, del Patrimonio Histórico Español.

4.2.7 Donativos o donaciones de bienes culturales de calidad garantizada, en favor de entidades, que persigan entre sus fines la realización de actividades museísticas, y el fomento y difusión del patrimonio histórico artístico.

El elenco es un poco reiterativo y crea dudas, por una parte, con la afirmación del punto tercero, se puede considerar incluido el punto quinto, y con el punto segundo los puntos quinto y sexto. 


\section{ENTIDADES BENEFICIARIAS DEL MECENAZGO}

Por una parte, tenemos las entidades a las que le es de aplicación el régimen fiscal especial establecido en el título II de la Ley; por otra parte, tenemos a los entes públicos; y en tercer lugar tenemos entidades, que por voluntad legal se han añadido por el transcurso del tiempo como beneficiarias de mecenazgo. Desde la publicación de la Ley, las entidades iniciales que con arreglo a la Ley 49/2002 pueden ser beneficiarias del mecenazgo, no ha hecho más que crecer a lo largo del tiempo. Con ello se ha creado un agravio comparativo, con otras entidades que cumplen objetivamente las mismas condiciones para ser beneficiarias de mecenazgo:

5.1. ENTIDADES SIN FINES LUCRATIVOS, A LAS QUE ES DE APLICACIÓN EL RÉGIMEN FISCAL ESTABLECIDO EN EL TÍTULO II DE LA LEY 49/2002

Estas entidades, además de cumplir los requisitos establecidos por el legislador, tienen que solicitar su inclusión. Es por tanto un régimen potestativo, y no obligatorio para todas las entidades que reúnan los requisitos para acogerse al mismo. Dichas entidades son:

\subsubsection{Las fundaciones.}

5.1.2. Las asociaciones declaradas de utilidad pública.

5.1.3. Las organizaciones no gubernamentales de desarrollo a que se refiere la Ley 23/1998, de 7 de julio, de Cooperación Internacional para el Desarrollo. Una Organización no Gubernamental de Desarrollo puede haberse constituido como fundación (estaría además incluida en el apartado 5.1.1.) o como asociación. Si fuera una asociación considero que no necesita alcanzar el requisito de ser declarada de utilidad pública, puesto que como ONGD está expresamente contemplada en un apartado específico. Lo único que es necesario es que esté legal y válidamente constituida y ello se produce con la inscripción en el correspondiente registro. Inscripción que supone el reconocimiento de que cumple todos los requisitos legales. Existen no obstante criterios dispares al 
respecto ${ }^{23}$. La Dirección General de Tributos, en consultas vinculantes contesta unas veces que es necesario, que la ONGD sea como asociación declarada de utilidad pública y otras que no ${ }^{24}$. La ley, lo que dice es "Las organizaciones no gubernamentales de desarrollo a que se refiere la Ley 23/1998, de 7 de julio, de Cooperación Internacional para el Desarrollo, siempre que tengan alguna de las formas jurídicas a que se refieren los párrafos anteriores". No existe una forma jurídica diferente porque una asociación sea o no declarada de utilidad pública. La forma es de fundación o asociación. La declaración de utilidad pública es una calificación, como mínimo de dos años después de la creación de la asociación. Una ONGD tiene como objeto claramente un fin de interés general, y que tenga que esperar unos años y una declaración administrativa especial, nos parece contrario al espíritu de la norma. Aunque lo mejor hubiera sido que el legislador hubiese redactado el precepto de forma clara.

5.1.4. Las delegaciones de fundaciones extranjeras inscritas en el Registro de Fundaciones. En este apartado, está claro que sólo tienen acceso al régimen privilegiado las fundaciones extranjeras, pero no las asociaciones.

5.1.5. Las federaciones deportivas españolas, las federaciones deportivas territoriales de ámbito autonómico integradas en aquellas, el Comité Olímpico Español y el Comité Paralímpico Español.

5.1.6. Las federaciones y asociaciones de las entidades sin fines lucrativos a que se refieren los párrafos anteriores.

\subsection{LOS ENTES PÚBLICOS QUE A CONTINUACIÓN SE ENUMERAN:}

5.2.1. El Estado, las Comunidades Autónomas y las Entidades Locales, así como los Organismos autónomos del Estado y las entidades autónomas de

23 Isidoro Martín Dégano, "La situación actual de los incentivos fiscales al mecenazgo en la legislación estatal. Reflexiones a futuro", En La dimensión social de la fiscalidad: discapacidad, tercer sector y mecenazgo (Estudios en homenaje a Miguel Cruz Amorós). Dir. Por Miguel Ángel Cabra de Luna. (Madrid: Editorial Cinca S.A.,2017), 216.

24 La Vo126-09 de 22/01/2009, es del criterio de que de una ONGD inscrita en el Registro oficial como tal ONGD, aunque su forma jurídica sea la asociación, no necesita ser declarada de utilidad pública, para poderse acoger el régimen fiscal privilegiado previsto en el título II de la Ley 49/2002. Por el contrario, la V2168-14 de 06/08/2014, tiene el criterio contrario. 
carácter análogo de las Comunidades Autónomas y de las Entidades Locales. Las universidades públicas y los colegios mayores adscritos a las mismas.

5.2.2. El Instituto Cervantes, el Institut Ramon Llull y las demás instituciones con fines análogos de las Comunidades Autónomas con lengua oficial propia.

5.2.3. Los Organismos Públicos de Investigación dependientes de la Administración General del Estado.

5.2.4.La Cruz Roja Española y la Organización Nacional de Ciegos Españoles.

5.2.5.Los consorcios Casa de América, Casa de Asia, "Institut Europeu de la Casa de la Mediterránia, y el Museo Nacional de Arte de Cataluña.

5.2.6. El Instituto de España y las Reales Academias integradas en el mismo, así como de las instituciones de las Comunidades Autónomas que tengan fines análogos a los de la Real Academia Española.

5.2.7. El Museo Nacional del Prado.

5.2.8. El Museo Nacional Centro de Arte Reina Sofía.

\subsection{ENTIDADES DE CARÁCTER RELIGIOSO:}

5.3.1. La Obra Pía de los Santos Lugares.

5.3.2.Las fundaciones propias de entidades religiosas inscritas en el Registro de Entidades Religiosas, que cumplan los requisitos de las entidades sin fines lucrativos establecidos en la Ley 49/2002

5.3.3. Las entidades de la Iglesia Católica contempladas en los artículos IV y $\mathrm{V}$ del Acuerdo sobre Asuntos Económicos suscrito entre el Estado español y la Santa Sede, y las entidades de otras iglesias, confesiones o comunidades religiosas, que tengan suscritos acuerdos de cooperación con el Estado español.

El elenco es consecuencia de la evolución histórica de la normativa reguladora de mecenazgo, y como suele ser normal en el campo de los beneficios fiscales, los mismos no dejan de crecer con el tiempo. En este punto resulta llamativo la 
incorporación de determinadas entidades. Concretamente llama la atención que los Museos públicos y en especial los Nacionales no sean entidades beneficiarias de Mecenazgo, salvo supuestos concretos que a continuación analizamos:

Por la disposición final 4 de la Ley 46/2003 de 25 de noviembre se añadió el Museo Nacional de Prado como entidad beneficiaria de mecenazgo. Por la disposición final 4 de la Ley 34/2011, de 4 de octubre se añadió como entidad beneficiaria de mecenazgo el Muso Nacional Centro de Arte Reina Sofía. Por el art. 6 de la Ley 62/2003, de 30 de diciembre se consideró entidades beneficiarias de mecenazgo "Institut Europeu de la Mediterrània" y el Museo Nacional de Arte de Cataluña.

Ahora bien, hay al menos 139 Museos en España pertenecientes a la Administración General del Estado. Además, las Comunidades Autónomas o bien tienen o bien han creado a partir de los años 80 sus museos. Podría justificarse el Prado o Reina Sofia por su carácter no de museos de la Comunidad de Madrid, sino estatales, patrimonio de toda España, pero ¿̇por qué considerar entidad beneficiaria de mecenazgo los de una comunidad autónoma como el museo nacional de Arte de Cataluña, cuando no tiene dicho privilegio ninguno de los siguientes museos:

Museo Arqueológico Nacional, Madrid.

Museo Nacional y Centro de Investigación de Altamira, Altamira, Cantabria

Museo Nacional de Arqueología Subacuática, ARQUA, Cartagena, Región de Murcia.

Museo Nacional del Traje, Centro de Investigación del Patrimonio Etnológico (CIPE), Madrid.

Museo Nacional de Artes Decorativas, Madrid.

Museo Nacional de Cerámica y de las Artes Suntuarias González Martí, Valencia.

Museo Nacional de Escultura, (anteriormente llamado: Museo Nacional Colegio de San Gregorio, Museo Nacional de Reproducciones Artísticas), Valladolid. 
Museo del Greco, Toledo.

Museo Casa de Cervantes, Valladolid

Museo Nacional de Arte Romano, Mérida, Badajoz.

Museo Sefardí, Toledo.

Museo Sorolla, Madrid

Museo Nacional de Antropología, Madrid.

Museo Cerralbo, Madrid

Museo del Romanticismo, Madrid

Museo de América, Madrid.

¿Por qué la Generalitat de Cataluña y la ciudad de Barcelona crean un consorcio para el "Institut Europeu de la Casa de la Mediterrània" y reciben el privilegio de ser entidad beneficiaria de mecenazgo a nivel nacional? Qué razón objetiva justifica este trato privilegiado, frente al resto de Comunidades Autónomas Españolas que tienen sus consorcios para la gestión de sus museos y entidades culturales... y no pueden dichos consorcios ser entidades beneficiarias de mecenazgo...

Lo lógico sería una norma como la establecida en el art. 16 de la Ley 49/2002 en sus apartados b) y d), que hizo extensiva la calificación de entidad beneficiaria de mecenazgo a todas las entidades, que por analogía son equivalentes de todas las comunidades autónomas. La calificación de entidad beneficiaria de mecenazgo debería, por tanto, ser aplicable a todos los museos nacionales, y de las comunidades autónomas de España, tanto de propiedad pública directa, como a través de los consorcios creados por los entes públicos para su gestión. Y no sólo como es aplicable al Museo del Prado, al Museo Reina Sofia, y a los consorcios Casa de América, Casa de Asia, "Institut Europeu de la Mediterrània", y el Museo Nacional de Arte de Cataluña. 


\section{OTRAS MODALIDADES DE MECENAZGO}

Además del mecenazgo común que hemos analizado hasta ahora, existen otras posibilidades como son:

\subsection{LAS ACTIVIDADES PRIORITARIAS DE MECENAZGO}

La ley de Presupuestos Generales del Estado cada año designa una serie de actividades realizadas por las entidades beneficiarias de mecenazgo relacionadas en el apartado anterior, que tienen derecho a un incremento de la deducción de las cantidades donadas en un $5 \%$. Vivimos unos años de prorrogas de presupuestos y con ellos de disposiciones de todo tipo, y como no de las actividades prioritarias de mecenazgo que, fijadas en 2018, se prorrogaron para el 2019 y por el art. 5 del Real Decreto-ley 18/2019, de 27 de diciembre para el año 2020. Estas actividades de conformidad con la Disposición septuagésima son:

6.1.1.Fomento, promoción y difusión de las artes escénicas y musicales, realizadas por las Administraciones públicas o con el apoyo de estas.

6.1.2. Las realizadas por el Instituto Cervantes, para la promoción y difusión de la lengua española, y de la cultura mediante redes telemáticas, nuevas tecnologías y otros medios.

6.1.3. Las realizadas por la Biblioteca Nacional de España en cumplimiento de sus fines y funciones de carácter cultural y de investigación científica.

6.1.4.Las realizadas por el Museo Nacional del Prado para la consecución de sus fines establecidos en la Ley 46/2003, de 25 de noviembre, reguladora del Museo Nacional del Prado y en el Real Decreto 433/2004, de 12 de marzo, por el que se aprueba el Estatuto del Museo Nacional del Prado.

6.1.5. La conservación, restauración o rehabilitación de los bienes del Patrimonio Histórico Español que se relacionaban en el anexo XIII de la Ley de Presupuestos Generales del Estado 2018. 
6.1.6. Las realizadas por la Fundación ONCE en el marco de la Bienal de Arte Contemporáneo, el Espacio Cultural «Cambio de Sentido» y la Exposición itinerante «El Mundo Fluye».

6.2. LOS CONVENIOS DE COLABORACIÓN EMPRESARIAL EN ACTIVIDADES DE INTERÉS GENERAL25

El artículo 25 de la Ley dispone 49/20202 que «se entenderá por convenio de colaboración empresarial en actividades de interés general, a los efectos previstos en esta Ley, aquel por el cual las entidades a que se refiere el artículo 16, a cambio de una ayuda económica para la realización de las actividades que efectúen en cumplimiento del objeto o finalidad específica de la entidad, se comprometen por escrito a difundir, por cualquier medio, la participación del colaborador en dichas actividades» .

Se trata de la entrega de una ayuda, que realiza una entidad empresarial a una entidad beneficiaria del mecenazgo, para que cumpla los fines de interés general, normalmente de interés social, que tiene como objeto la entidad beneficiaria, con el requisito de que difunda la participación de la entidad prestaría de la ayuda en la actividad de interés general que se realiza. No deja de ser un instrumento de publicidad de la entidad, que hace la ayuda, que además cumple con su responsabilidad social corporativa. Es obligatorio, que en el propio convenio se especifique el proyecto concreto para el que se entrega la ayuda de la entidad colaboradora, debiendo destinarse la misma a dicho proyecto.

La ayuda que la empresa realiza tiene que ser adecuada a contribuir para la realización de las actividades que la entidad beneficiaria realiza. Si la ayuda es dineraria, o consiste en pagar directamente los gastos necesarios para el desarrollo de la actividad de interés, siempre va a cumplir tal requisito, pues el dinero como bien fungible o el pago directo del coste, es totalmente adecuado para destinarlo a lo necesario al desarrollo de la actividad de interés general. Si se trata

25 Juan Calvo Vérgez, "La tributación de los convenios de colaboración empresarial en actividades de interés general como instrumento de mecenazgo", Zergak 41(2011): 100. 93-130 
de ayuda en especie ya se hay que comprobar que la misma cumple el requisito de idoneidad.

El requisito fundamental es el fin de la ayuda económica. Es una ayuda afectada a la realización de las actividades, que realizan en cumplimiento del objeto o finalidad de la entidad beneficiaría, que tiene que ser de interés general.

Por último, estamos ante un negocio jurídico bilateral y oneroso, porque existe la contraprestación de difundir por cualquier medio la participación de la entidad empresarial prestataria de la ayuda, en la actividad de interés general que desarrolla la entidad sin ánimo de lucro receptora de la ayuda.

Cabe preguntarse si la difusión tiene que realizarla forzosamente la entidad sin ánimo de lucro receptora de la ayuda, o puede también la entidad empresarial que da la ayuda, utilizar los logos de la entidad sin ánimo de lucro. En este punto existen posturas contrapuestas como se ha puesto de manifiesto por otros autores $^{26}$. La Dirección General de Tributos en la consulta 0939-04 de 13 de abril de 2004 JT 2004, 68 lo admita y en la consulta de 3 de diciembre de 2045-042004 JT 2005, 211 y otras posteriores, lo rechaza. La norma está clara y aplicando el aforismo latino "In claris non fit interpretatio" no cabe que la empresa que da la ayuda use los logos y haga directamente publicidad para dar a conocer la ayuda económica que presta, pues el artículo 25 afirma que es la entidad sin ánimo de lucro la que tiene que cumplir tal función.

\section{CONSECUENCIAS QUE PUEDE GENERAR LA REFORMA DEL MECENAZGO DE 5 DE MAYO DE 2020}

La Ley 49/2002 entró en vigor el 25 de diciembre de 2002, con lo cual el primer año completo de vigencia y aplicación es el año 2003. Los resultados en la primera década no fueron alentadores en cuanto decreció en el Impuesto sobre la Renta de las Personas Físicas el número de declaraciones con derecho a deducir

26 Félix Plaza Romero y José María Cobos Gómez, "Los convenios de colaboración empresarial en actividades de interés general", Revista Aranzadi de derecho de deporte y entretenimiento 49 (2015): 640 . 
por gastos e inversiones de interés cultural, y descendieron las cantidades donadas. En el Impuesto de Sociedades por el contario creció el número de declaraciones con derecho a deducción, aunque la media de la deducción se redujo. ${ }^{27}$

La reforma del año 2014, y la llevada a cabo en mayo del presente año 2020, han generado y van a generar un incremento del número de donantes y de las cantidades donadas para las grandes entidades nacionales y supranacionales, me refiero Unicef, Aldeas Infantiles, SOS, Acción contra el hambre, Caritas, Cruz Roja, ... la mayor parte de las cuales se han apresurado a poner en la primera pantalla, que sale en internet en sus páginas Web "Los primeros $150 €$ que dones desgravarán el 80\% “. Puede ser que algunos ciudadanos estén pensando que a cada ONG que dona 150 euros va a conseguir recuperar el 80\%. Y se van a llevar la sorpresa que las primeras 150 euros, si van a tener el $80 \%$, pero si dona a otra entidad ya será o $35040045 \%$, depende.... Aquí surgen más y más problemas.

Pongamos un supuesto práctico: Un donante hace aportaciones de 200 euros a tres entidades que dan derecho a deducción, en total 600 euros. A la primera entidad lleva años donando 200 euros, y realiza una actividad prioritaria de mecenazgo, a la segunda entidad lleva años donando, y no es prioritaria de mecenazgo, y a la tercera entidad es la primera vez que dona, y no es prioritaria de mecenazgo. ¿cómo aplicar la desgravación? ¿en qué orden? El orden que más le interesa al contribuyente es: primero 150 euros de la entidad que dona por primera vez. Así consume el $80 \%$ del $75 \%$ de la entidad que no tiene en el exceso un $45 \%$. A continuación, los 200 euros de la entidad que tiene un $45 \%$, porque si se hace al revés y el $80 \%$ se deduce de la entidad fidelizada con actividad prioritaria de mecenazgo los 200 euros ya sólo se puede aplicar el $45 \%$ a 50 euros y no a 200.

$\mathrm{Y}$ es que todo entra en un saco, pero el dinero es fungible y lo que suma como cantidad total es sobre la que hay que aplicar diferentes porcentajes, $80 \%, 35 \%$,

27 Pau Rausell Köster, Julio Montagut Marqués y Tomás Minyana Beltrán "Hacia un nuevo modelo de financiación cultural. ¿Renovar el mecenazgo?” Periférica: Revista para el análisis de la cultura y el territorio, N. ${ }^{\mathrm{O}} 14$, (2013): 217 
40\% y $45 \%$ y ello a diferentes tramos. Según se decida aplicar se deducirá más o menos. O sea, un caos, que va provocar tratamientos discriminatorios, y desde luego contrarios a los que el ciudadano espera.

No se pueden establecer para las deducciones cuatro porcentajes en función de circunstancias distintas, según las entidades a las que se dona, sin que esté previsto un orden para aplicar los porcentajes.

Otra situación problemática es un ciudadano especialmente generoso, que decida realizar importantes donativos en un año y se encuentre que supera el 10\% de su base liquidable, porque queda derecho a deducir una parte de lo donado. Pero que parte. ¿Por qué las cantidades donadas que dan derecho a deducir pueden deducir al 35\%, al $40 \%$ o al $45 \%$ ? Además, téngase en cuenta, que, en puridad de conceptos, no es que las cantidades con derecho a deducción queden simplemente limitadas al $10 \%$ de la base liquidable, sino que lo que la ley exactamente dice es "la base de esta deducción se computará a efectos del límite previsto en el apartado 1 del art. 69 de la ley 35/2006 de 28 de noviembre del Impuesto sobre la Renta de las Personas Físicas". Ese apartado dispone "La base de las deducciones a que se refieren los apartados 3 y 5 del artículo 68 de esta Ley, no podrá exceder para cada una de ellas del 10 por ciento de la base liquidable del contribuyente." O sea que el 10\% es conjunto para todo lo que está incluido dentro de cada bloque 3 y bloque 5, lo que implica que el campo es aún más limitado. Ello crea especialmente problemas en los grandes donantes, no en pequeños donantes. El ministerio de cultura y deporte, viene a través de sus representantes públicamente manifestando que persiguen el objetivo de impulsar el micro mecenazgo. Es estupendo que se persiga este objetivo, pero me parece, que es tan estupendo al menos, como perseguir a la vez el objetivo de impulsar todo el mecenazgo, el micro mecenazgo, el mecenazgo llamemos normal, y el gran mecenazgo. Todos deben impulsarse, y para ello tiene que hacerse un tratamiento diferenciado, porque diferentes son los circunstancias de los pequeños, de los medianos y de los grandes mecenas.

La falta de eficacia de la reforma en crear en la ciudadanía de este país una mentalidad de mecenazgo, se debe a mi criterio, además de a estos problemas, 
originados por reformas puntuales que no tienen en cuenta la coordinación interna de la ley 49/2002, como la falta de planificación, ordenación, e impulso al mecenazgo. Por ello, el incremento de donaciones, es de los mismos donantes, a las mismas entidades. También hago constar, que, desde la administración, no se han hecho las campañas informativas en los medios de comunicación concienciando a los ciudadanos. Las ONG, Fundaciones, y grandes entidades beneficiarias del mecenazgo social y sanitario si han hecho intensas compañas de información a los donantes persona a persona. El señuelo de que, de los 150 primero euros donados, el Estado devuelve el 80\% (por tanto, el donante sólo dona 30 euros porque el Estado le devuelve en su declaración 120 euros) es muy atractivo. Sobre todo, anima a incrementar la cuantía de la donación cuando es inferior a 150 euros. Pero, además, que el exceso por encima de 150 euros y hasta el 10\% de la base liquidable del donante, genere un 35\% de desgravación es otro señuelo. Y redondeando el atractivo que ese $35 \%$ si se donó a la misma entidad igual o mayor cantidad en los dos ejercicios anteriores pase del 35\% al 40\% está bastante bien. Que encima si se trata de actividad prioritaria de mecenazgo exista otro $5 \%$ de incremento tiene mayor aliciente. Evidentemente los incentivos podían ser mayores, pero no se puede negar que tienen ya un buen nivel. Un nivel en el que estaría justificado un gran incremento, no sólo en las cantidades donadas a entidades beneficiarias del mecenazgo, sino en un incremento espectacular en su número. O sea, un efectivo desarrollo del micro mecenazgo. Sin embargo, los resultados no son parejos con los incentivos y ello es, y lamento insistir, porque no es sólo cuestión de incentivos

A pesar de la situación que tenemos en España en estos momentos, defiendo que el mecenazgo es un instrumento con un enorme potencial para compensar la escasez de recursos públicos ${ }^{28}$. Con una eficaz normativa mercantil, administrativa y fiscal, incentivando el mecenazgo ${ }^{29}$ se puede avanzar mucho en

28 Alejo Hernández Lavado," Una nueva fiscalidad para fomentar la participación ciudadana en la cultura y el patrimonio cultural a través de las asociaciones: La reforma fiscal italiana y española de 2016”. Patrimonio Cultural y Derecho no 17 (2013): 220.

29 Alejo Hernández Lavado, "El crowfunding o micro mecenazgo como instrumento de puesta en valor de la cultura y el patrimonio cultural y su fiscalidad” en Entidades con valor social: nuevas perspectivas tributarias. dir 2017), 367. 
el futuro. Pero a la vez con adecuadas campañas de sensibilización para estimular la generosidad y el altruismo. Para mí un ejemplo de sensibilización eficaz es la que ha llevado Italia con el programa público Arts Bonus. Los exquisitos videos televisivos, convocando al mecenazgo. Las campañas desde los Ayuntamientos con todo tipo de carteles, programas de mano, y llamadas al mecenazgo. Los reconocimientos públicos y los premios han generado un buen resultado. Y la visibilidad de una página Web "Il Ministero per i Beni Culturali e Ambientali., creado en 1974, en la que en tiempo real puedes ver el crecimiento de los diferentes programas de mecenazgo, con las cantidades que van donando y la identificación de los donantes. Los premios, concursos, etc. generan una sensibilización en la población. Independientemente del gran mecenazgo de las corporaciones empresariales.

\begin{tabular}{|c|c|c|c|c|c|}
\hline AÑO & TOTAL & $\begin{array}{l}\text { Donantes de } \\
\text { más de } \mid 100.000\end{array}$ & $\begin{array}{l}\text { Donantes } \\
10.000 \text { a } 100.000\end{array}$ & $\begin{array}{l}\text { Donantes de } \\
1.000 \text { a } 10.000\end{array}$ & $\begin{array}{l}\text { Donantes de } \\
\text { menos de } 1.000\end{array}$ \\
\hline 2014 & 442 & 6 & 16 & 11 & 14 \\
\hline 2015 & 1815 & 45 & 111 & 224 & ¿? \\
\hline 2016 & 2330 & 48 & 135 & 398 & ¿? \\
\hline 2017 & 2873 & 63 & 211 & 490 & ¿? \\
\hline 2018 & 3199 & 79 & 267 & 559 & ¿? \\
\hline 2019 & 4068 & 101 & 355 & 652 & ¿? \\
\hline 2020 & 3450 & 71 & 181 & 139 & ¿? \\
\hline
\end{tabular}

Tabla 3. Elaboración propia a fecha 20 de diciembre de 2020, con los datos públicos de la página oficial Italiana del Ministero per i beni e le attività cultturali e per il turismo. https://artbonus.gov.it/i-mecenati.html?year=2020.

De la tabla 3 se desprende que hay un continuo incremento desde el año 2014, en que al igual que en España, se reforma el mecenazgo en Italia, hasta el año 2020. En cuanto a los donantes de cantidad superior a 100.000 o sea gran mecenazgo la caída va a ser en torno al 15\%, En el tramo siguiente se acentúa la caída que es superior al 50\% y para los donantes entre 10.000 y 100.000 euros aún se acentúa más la caída que amenaza superar el 75\%. Por tanto, la tendencia es que, en momentos de crisis, resisten más los grandes mecenas que los pequeños. Esta tabla no puede compararse con las anteriores respecto al mecenazgo español, pues en España los datos se refieren a todo tipo de mecenazgo, mientras que esta tercera tabla, sólo se refiere al mecenazgo cultural público italiano. 
Resumiendo, no basta con incentivos fiscales, es necesario planificación, eficacia y eficiencia administrativa en la información, formación y control del mecenazgo. El mecenazgo requiere que la administración desarrolle una intensa labor para formar, informar, ayudar, simplificar, facilitar, controlar, etc. todo el proceso30. Por tanto, hay que trabajar desde todos los campos: económico, fiscal, social, etc. Hay que remover obstáculos, y despertar en el ciudadano la necesidad de colaborar desde el altruismo y la generosidad ${ }^{31}$.

No quiero acabar este apartado con negatividad. Es cierto que la ciudadanía de este país no acaba de incorporarse al mecenazgo, sobre todo cultural, pero no por ello dejamos de encontramos magníficos ejemplos de mecenazgo en el campo social, deportivo, y en el campo de la cultura y del patrimonio cultural. Y esto es una realidad tanto a nivel de grandes fortunas, como de mujeres extraordinarias ${ }^{32}$, como de ciudadanos económicamente modestos pero generosos.

\section{PROPUESTAS DE LEGE FERENDA PARA CONSEGUIR POTENCIAR EL MECENAZGO EN ESPAÑA}

El Parlamento Europeo tiene una enorme preocupación con el mecenazgo y por ello en nota recojo sus indicaciones más importantes. A la vez viene instando a los estados miembros, entre ellos España, a que establezcan normas fiscales que fomenten la inversión privada en la cultura y el patrimonio cultural33. Habría que

30 Alejo Hernández Lavado, "Financiación y protección del patrimonio histórico: propuestas de futuro". En Haciendas Locales y Patrimonio Histórico y Cultural. Dir. F. Álvarez Arroyo (Madrid: Dykinson, 2017), 240.

31 http://www.culturalab.org/uploads/1/o/5/1/10513475/recensione_02_2010.pdf consultado el 1 de agosto de 2019.

32 El Museo de Orsay en Paris tiene una plataforma sólo para el mecenazgo de las mujeres. https://www.musee-orsay.fr/es/info/mecenazgo/circulo-de-las-mujeres-mecenas.html. consultada el 24 de septiembre de 2019.

33 El Diario Oficial de las Comunidades Europeas $\mathrm{N}^{\circ} \mathrm{C} 336 / 1$ I (Comunicaciones) CONSEJO CONCLUSIONES DE LOS MINISTROS DE CULTURA REUNIDOS EN EL SENO DEL CONSEJO el 12 de noviembre de 1992 sobre las directrices para la actuación cultural comunitaria, estableció entre otras las siguientes conclusiones: “... la actuación cultural de la Comunidad deberá respetar las diversidades nacionales y regionales y simultáneamente poner en primer plano el patrimonio cultural común. Ello supone un enfoque que se centre en una gama de actuaciones a escala comunitaria destinada a fomentar las actividades culturales en todos los Estados miembros y a alentar la cooperación entre éstos." "desarrollar más el tema del mecenazgo empresarial de las artes”. A su vez el $\mathrm{N}^{\circ} \mathrm{C}$ 320/2 Diario Oficial de las Comunidades Europeas 13.12.86 RESOLUCIÓN de los ministros de 
hacer un esfuerzo para aproximarnos a los niveles en que el mecenazgo se está desarrollando en Inglaterra con entidades privadas como National Trust (National Trust for Places of Historic Interest or Natural Beauty) que celebra en el año 2020, nada menos que 125 años de mecenazgo cuidando la naturaleza, el arte, y la historia34, o Italia con el Fondo Ambiente Italiano. Una entidad creada en un país latino para preservar el patrimonio cultural35 que está consiguiendo crear en Italia junto con Art Bonus ${ }^{36}$ una mentalidad de mecenazgo cultural. Y por citar un tercer país, Francia que con la FONDATION DU PATRIMOINE, realiza una multiplicidad de funciones, para promover el mecenazgo.

Lo importante, es una gestión de desarrollo integral del mecenazgo, que no se quede en unos mayores o menores beneficios fiscales, sino que incorpore una multiplicidad de instrumentos de promoción, fidelización e impulso del

cultura, reunidos en el seno del Consejo de 13 de noviembre de 1986 relativa al patrocinio empresarial de actividades culturales afirma entre otras cosas: 1. Los Ministros de cultura, reunidos en el seno del Consejo, reconocen que la herencia cultural y las actividades culturales europeas en general gozan de una combinación de apoyos públicos y privados. A su juicio, la mejor manera de mantener y desarrollar dicho patrocinio es intensificando los apoyos de variada procedencia, incluyendo diferentes formas de mecenazgo tanto público como privado. La Resolución del Parlamento Europeo, de 12 de septiembre de 2013, sobre el fomento de los sectores europeos de la cultura y la creación como fuentes de crecimiento económico y empleo (2012/2302(INI)) (2016/C 093/13) publicado 9.3.2016 en el diario Diario Oficial de la Unión Europea C 93/95 en el apartado 42. Insta a los Estados miembros a buscar medidas alternativas de financiación para los SCC, especialmente en tiempos de crisis; en este sentido, considera que el mecenazgo podría ser una alternativa válida; y, Pietro

34 En 1895 tres ciudadanos: Octavia Hill, Robert Hunter y Hardwicke Rawnsley (un trabajador social, un abogado, y un clérigo) se comprometieron a preservar los lugares históricos y naturales de Inglaterra, no sólo para salvarlos, sino para que todo el mundo pudiera disfrutarlos. 125 años después esta institución benéfica privada, dedicada a preservar el patrimonio cultural y natural ha recuperado y mantiene: 780 millas de costa, 250.000 hectáreas de tierra, 500 casas históricas, castillos, parques y jardines y casi 1.000.00o de obras de arte. Con 5.597.985 miembros y más de 4.000.0oo de libras recibidas al año en legados, subvenciones, etc., Los socios con más de 26 años pagan al año 72 libras, los jóvenes entre 18 y 25 años 36 libras y de 5 a 17 años 10 libras. Con una gran amplitud de posibilidad de donación a partir de eventos de todo tipo. Como consecuencia de ellos con unos grandes recursos y una gran cantidad de actividades. https://www.nationaltrust.org.uk/ consultada por última vez el 27 de enero de 2020.

35 El Fondo Ambiente Italiano que ha conseguido crear delegaciones en Francia, Suiza, Inglaterra y Estados Unidos para desde el voluntariado cultural conseguir salvar el patrimonio cultural italiano. Creado el 28 de abril de 1975 por Giulia María Mozzoni Crespi, Renato Bazzoni, Alberto Predieri e Franco Russoli. Con más de 150.000 socios entre ciudadanos y empresas, con 64 lugares del patrimonio cultural recuperados, 31 bienes que, abiertos al público, 21 bienes tutelados, 12 bienes en restauración y más de 122 millones de euros de donaciones invertidos en restaurar el patrimonio cultural y natural es otro modelo a seguir. https://www.fondoambiente.it/il-fai/storia/ página consultada por última vez el 27 de enero de 2020.

36 Alejo Hernández Lavado, "El nuevo mecenazgo italiano de la cultura, el arte y el patrimonio cultural", Patrimonio Cultural y Derecho N. ${ }^{\circ} 23$ (2019): 220. 
mecenazgo y de una mentalidad de mecenazgo que es tan débil en España en contraposición a otros países.

\subsection{LAS MEDIDAS CONCRETAS DE PROMOCIÓN DEL MECENAZGO, QUE SE DEBERÍAN} TOMAR SON:

8.1.1. Regular separadamente el mecenazgo social, cultural y deportivo, por ser realidades diferentes. Realidades que tienen puntos en común, pero necesitan un tratamiento diferenciado.

8.1.2. Subsidiariamente a lo anterior habría que hacer una ley especial de Mecenazgo en el ámbito cultural. La cultura hoy, tiene una conexión directa con el respeto a la diversidad, con el respeto a la naturaleza, con la generosidad y con el compromiso en la defensa de la libertad y de la democracia. Tenemos además situaciones de extrema fragilidad y vulnerabilidad como la que está generando el cierre de cientos de conventos y monasterios que han mantenido durante siglos un patrimonio cultural excepcional37, que está en riesgo de perderse.

8.1.3. Hay que impulsar y potenciar la figura del Mecenas $3^{8}$, con reconocimientos especiales y retornos simbólicos gratificantes, más espiritualmente que materialmente, lo que impide la normativa actual. Las compensaciones deberían admitirse hasta un $25 \%$ de la donación, tal y como se admite en Francia.

8.1.4. Regular la realización de eventos de captación de fondos, que tanto éxito tienen en el mundo anglosajón, como cenas de recaudación y que con el tratamiento fiscal existente en España son absolutamente inviables.

8.1.5. Ampliar el número de entidades receptoras de mecenazgo a las asociaciones que sólo desarrollen actividades de interés general sin ánimo de

37 Un listado de los conventos cerrados entre 2000-2019 se puede consultar en https://divinavocacion.blogspot.com/2018/o2/monasterios-y-conventos-clausurados-en.html?m=1 . Ultima fecha de consulta 20 de enero de 2020.

38 Isabel Peñalosa Esteban y Teresa Sanjurjo González "La fiscalidad de las fundaciones...,201. 
lucro. O sea, entidades que todos sus ingresos quedan afectos a los gastos necesarios para el desarrollo de las actividades de interés general. Quiero decir que, si una entidad no lucrativa que sólo desarrolla actividades de interés general, por imperativo legal tiene que tener un certificado digital, unos medios electrónicos y una conexión a internet, y demás gastos directos para el cumplimiento de sus obligaciones administrativas, contables y fiscales, todo ello al ser imprescindible, para el desarrollo de la actividad de interés general, tiene que considerarse como destinado a ello. En suma, cualquier entidad sin ánimo de lucro que realice una actividad que desarrolle un fin de interés general, sin lucro para nadie, y sólo generando beneficios a la sociedad tiene que ser receptora del mecenazgo, eliminando el absurdo requisito de declaración de utilidad pública que impide a más del 90\% de las entidades no lucrativas de España ser entidad receptora de mecenazgo. Ello además cortaría la corruptela de transformación o creación de Fundaciones para entidades cuya figura jurídica adecuada es la de la Asociación, pero que se constituyen en Fundaciones, para que sus donantes puedan tener el derecho a deducir por sus donaciones.

8.1.6. Que los Museos y otras entidades culturales puedan ser receptoras de mecenazgo.

8.1.7. Que los artistas puedan ser receptores de mecenazgo para poder desarrollar sus proyectos. Un proyecto artístico creativo puede no ser rentable, pero si tremendamente valioso para la sociedad. Si la sociedad lo elige para sus donaciones por su interés, porque no puede tener incentivos al mecenazgo. Aunque sea otorgando este derecho a proyectos que previamente pasan una evaluación positiva de su valor.

8.1.8. Que los consorcios contemplados en el art. 118 de la Ley 40/2015 de 1 de octubre, de Régimen Jurídico del Sector Público, en cuanto entidades de derecho público puedan ser beneficiarias de mecenazgo. Curiosamente en la realidad práctica en las Comunidades Autónomas se ha utilizado precisamente la figura del consorcio para gestionar entidades culturales como sitios arqueológicos, museos, festivales de música, teatro, etc. y resulta incongruente que queden excluidas del mecenazgo por una falta de previsión legal. El consorcio justamente 
es ente público que tiene una gestión muy dinámica y ser beneficiario del mecenazgo sería muy útil.

8.1.8. las grandes donaciones, tan importantes en Italia, Francia, Inglaterra, Estados Unidos, etc. que en España siguen incorrectamente tratadas.

\subsection{MEDIDAS INCENTIVADORAS EN LOS ASPECTOS FISCALES DEL MECENAZGO:}

8.2.1. Incrementar los porcentajes de deducción de las donaciones. En el Impuesto sobre la renta de las personas físicas los primeros 150 euros deberían deducir al 100\%, y el exceso al 65\%. En el Impuesto sobre Sociedades la deducción debería ser del $65 \%$. Y en el Impuesto sobre la Renta de No residentes las deducciones deben ser una trasposición de las anteriores, en función de que el no residente sea un contribuyente, con o sin establecimiento permanente.

8.2.2. Aumentar los límites de deducción al $20 \%$, pues el 10\% actual de la base liquidable en el Impuesto sobre la Renta de las Personas Físicas impide las grandes donaciones, creando una situación especialmente grave en las donaciones de 30.000 euros o más en los promotores de fundaciones. Igualmente elevar el límite del 10\% de la base imponible al 15\% en el Impuesto sobre Sociedades.

8.2.3. Permitir a las personas físicas, que lo que no pueden desgravar en un ejercicio, por superar el límite, puedan deducirlo al menos en los ejercicios siguientes hasta la prescripción del gravamen. E incluso se podría unificar el plazo de 10 años que actualmente existe para las personas jurídicas, en el Impuesto de Sociedades.

8.2.4. Considerar donaciones las prestaciones de servicios gratuitas. Las prestaciones de servicio tienen un campo de aplicación muy amplio en el mundo empresarial 39 , dejando espacios para actividades, poniendo medios materiales y

39 Alejandro Blázquez Lidoy, "La no-revisión de la Ley de Mecenazgo: historia de una reforma inconclusa” IUS CANONICUM, Vol. 55 núm. 109 (2015): 218. 
humanos para la realización de actividades, servicios pro-bono por parte de profesionales de toda índole: médicos, psicólogos, abogados, contables, etc.

8.3. ELIMINAR LA CONFLICTIVIDAD Y EL MALESTAR SOCIAL QUE HA GENERADO LA APLICACIÓN DE LA LEY 49/2002 A TRAVÉS DE LA REFORMA LLEVADA A CABO POR LEY 27/2014, DE 27 DE NOVIEMBRE, DEL IMPUESTO SOBRE SOCIEDADES:

8.3.1. La existencia de miles de entidades dedicadas desde la generosidad y el altruismo a fines de interés general, como atención a la juventud, a sectores vulnerables, a la cultura, pero que no reúnen los exigentes requisitos de la ley 49/2002, que se encuentran en situación de inferioridad ante la administración en general y en especial la tributaria. Siempre la administración ha sido un ente privilegiado, acostumbrado a actuar desde una situación de superioridad. Pero en estos momentos la administración está aprovechando, al contar con unos recursos infinitamente superiores al ciudadano para no sólo usar, sino obligar a usar unas tecnologías punteras informáticas que agrandan la brecha con el administrado. El administrado se siente más que nunca en situación de inferioridad. Por cierto, que el término Administración engloba mucho, y tampoco se puede decir que toda la administración española esté cumpliendo y al día con las nuevas tecnologías. Tenemos la paradoja de una legislación que obliga a entenderse electrónicamente con la administración y hay administraciones punteras tecnológicamente, como el Ministerio de Hacienda, pero otras no están cumpliendo la ley. Así podemos constatar por una parte el incumplimiento de la ley de determinadas administraciones, sin que ello genere sanciones ni exigencias de responsabilidad. Y sin embargo los administrados están siendo sancionados por no entenderse electrónicamente con la administración. Algo que es en primer lugar un interés, y una comodidad de la administración, y una carga más, a veces demasiada pesada, para los administrados más vulnerables.

8.3.2. Por último, para avanzar en este mundo cada vez más tecnológico y online, hay que crear instrumentos de asistencia al administrado, que carece de formación jurídica, técnica, e informática para que se pueda equilibrar la situación de inferioridad y desamparo. 


\section{REFERENCIAS BIBLIOGRÁFICAS}

Blázquez Lidoy, Alejandro. "La no-revisión de la Ley de Mecenazgo: historia de una reforma inconclusa”. Ius Canonicum 55, Núm. 109 (2015): 197-229.

Battelli, Ettore. "I soggetti privati e la valorizzazione del patrimonio culturale" en Patrimonio culturale profili giuridici e tecniche di tutela, a cura di Ettore Battelli, BarBara Cortese, andrea Gemma, antonella massaro. 53-89. Roma: Romatre-Press, 2017.

Boria, Pietro. "Il sistema tributario". En Diritto Tributario. Direc. Fantozzi.17-55 Torino: UTET, 2012.

Bustamante García, Agustín. La arquitectura clasicista del foco vallisoletano (1541-1640). Valladolid: Institución Cultural Simancas, 1983.

Cabra de Luna, Miguel A. "La regulación y funcionamiento de las fundaciones. Las fundaciones de titularidad pública. Especial referencia a las fundaciones públicas sanitarias”. Revista española de control externo 3, No 8, (2001): 29-94.

Cabrera Sánchez, Margarita. "El problema converso en Córdoba. El incidente de la Cruz del Rastro”, en La Península Ibérica en la era de los Descubrimientos. 331-339. Dir. por Manuel González Jiménez. Actas de las III Jornadas Hispano portuguesas de Historia Medieval. Vol. I. Sevilla, 1997.

Cabrera Sánchez, Margarita. "Los conversos de Córdoba en el siglo XV: la familia del jurado Martín Alfonso". Anuario de Estudios Medievales 35 (2005): 185-232.

Calvo Vérgez, Juan. "La tributación de los convenios de colaboración empresarial en actividades de interés general como instrumento de mecenazgo”. Zergak 41 (2011): 93-130.

Campo del Pozo, Fernando. "Hospital y Fundación Simón Ruiz en Medina del Campo (Valladolid)". En La Iglesia española y las instituciones de caridad. 491-510. Coord. por Francisco Javier Campos y Fernández. Sevilla: Real Centro Universitario EscorialMaría Cristina. Ediciones Escurialenses, 2006.

Diez González, María del Carmen. Arquitectura de los conventos franciscanos observantes en la provincia de Cáceres (s. XVI y s. XVII). Cáceres: Universidad de Extremadura, 2003.

Fidone, Gianfrancesco. "Il ruolo dei privati nella valorizzazione dei beni culturali; dalle sponsorizzacioni alle forme di gestione". Aedon Rivista di arte e diritto on line número 1-2 2012, 1-16. http://www.aedon.mulino.it/

García Chico, Esteban. Catalogo Monumental de la Provincia de Valladolid, Tomo IV. Partido Judicial de Medina del Campo. Valladolid: Diputación de Valladolid, 1964.

González Torrico, Antonio Jesús. "La Nobleza cordobesa y el patronazgo religioso”. Revista de estudios de ciencias sociales y humanidades 30 (2013): 79-92. 
Hernández Lavado, Alejo. "El nuevo mecenazgo italiano de la cultura, el arte y el patrimonio cultural". Patrimonio Cultural y Derecho 23 (2019): 267-300.

Hernández Lavado, Alejo," Una nueva fiscalidad para fomentar la participación ciudadana en la cultura y el patrimonio cultural a través de las asociaciones: La reforma fiscal italiana y española de 2016”. Patrimonio Cultural y Derecho 17 (2013): 215-235.

Hernández Lavado, Alejo. "Financiación y protección del patrimonio histórico: propuestas de futuro”. En Haciendas Locales y Patrimonio Histórico y Cultural. Dir F. Álvarez Arroyo. Madrid: Dykinson, 2017.

Hernández Lavado, Alejo. "El paisaje como patrimonio cultural y su protección en España a través del tributo". Dir. S Berroci y S Van Riel. 1199-1207. Tomo III. Firenze: Altralinea edizioni s.r.l., 2014.

Herreros Moya, Gonzalo J. "La reconstrucción del patrimonio judeoconverso. La familia, la casa y la capilla catedralicia de los Muñoz de Velasco en Córdoba”. Historia y Genealogía 8 (2018): 206-230.

Hurtado de San Antonio, Ricardo. El Monasterio de San Francisco de Cáceres. Cáceres: El Brocense, 1981.

Lagunas, Cecilia y Gonzalo Granara. "María de Ávila mujeres nobles, patrimonio y poder en el siglo XV”. Magallanica: revista de historia moderna 4 (2016) 152-163.

Manresa y Navarro, José María. Comentarios al Código Civil Español, Tomo I (1-709) de XII tomos. Madrid: Editorial Reus,1931.

Madoz, Pascual. Diccionario geográfico-estadístico-histórico de España y sus, posesiones de ultramar (1845-1850)-Madoz, Pascual, 1806-1870. Facsímil de 1845-1850. Valladolid: Establecimiento tipográfico de P. Madoz y L. Sagasti,1984.

https://bibliotecadigital.jcyl.es/i18n/consulta/resultados_navegacion.cmd?busq_autoro bra=CYLA20090074910\&descrip_autorobra=Obras\%20como\%20autor:\%20Madoz, \%20Pascual,\%201806-1870

Márquez Sillero, Carmen. La exención de las Fundaciones en el Impuesto sobre Sociedades. Conforme a la Ley 49/2002. Edición $n^{\circ}$ 1. Madrid: La Ley, mayo 2007.

Martín Dégano, Isidoro, "La situación actual de los incentivos fiscales al mecenazgo en la legislación estatal. Reflexiones a futuro”. En La dimensión social de la fiscalidad: discapacidad, tercer sector y mecenazgo (Estudios en homenaje a Miguel Cruz Amorós). Dir. por Miguel Ángel Cabra de Luna. 215-241. Madrid: Cinca, 2017.

Palacios Ronda, Esteban. "Utilidad Pública de las asociaciones. Revocación por la Administración y solución fundacional" REVESCO. Revista de Estudios Cooperativos 5, No. 130, (2019): 99-121. https://core.ac.uk/download/pdf/162 288323.pdf 
Peñalosa Esteban, Isabel y Teresa Sanjurjo González. "La fiscalidad de las fundaciones: evolución, situación actual y perspectivas de futuro”. En La dimensión social de la fiscalidad: discapacidad, tercer sector y mecenazgo (Estudios en homenaje a Miguel Cruz Amorós). Dir. por Miguel Ángel Cabra de Luna. 195-214. Madrid: Cinca, 2017

Plaza Romero, Félix y José María Cobos Gómez. "Los convenios de colaboración empresarial en actividades de interés general". Revista Aranzadi de derecho de deporte y entretenimiento 49 (2015): 635-642.

Querol García, María Teresa. "Régimen fiscal de las entidades sin fines de lucro y de los incentivos fiscales al mecenazgo". Carta Tributaria - Monografías 3 (Quincena del 1 al 15 Feb. 2008): 3-34.

Rausell Zóster, Pau; Julio Montagut Marqués y Tomás Minyana Beltrán. "Hacia un nuevo modelo de financiación cultural. ¿Renovar el mecenazgo?”. Revista para el análisis de la cultura y el territorio 14 (2013): 209-233

Ruiz Gálvez, Ángel María. "Los estudios sobre el patrimonio judeoconverso en la corona de Castilla: las promociones artísticas como instrumento de integración social (ss. XVXVII)”. Mediterranea - ricerche storiche - 46 Anno XVI - Agosto (2019): 220-250.

Scanu, Giuseppe. "Dalla leva fiscale regionale un possibile volano per la promozione del patrimonio culturale e lo sviluppo economico territoriale". Rivista trimestrale di diritto tributario 2 (2018): 401-416.

Soto Moya, María del M. "Incentivos fiscales al micromecenazgo digital como fórmula de colaboración social “. En Fiscalidad de la Colaboración Social. Coordinada por José Pedreira Menéndez y Pascual González. 47-74. Pamplona: Aranzadi, 2018.

Vicente Hernández, Álvaro. Poseedores de Títulos e Grandezas: La Imagen de la Nobleza en los Territorios de Murcia. Tesis doctoral en acceso abierto en https://digitum.um.es/digitum/handle/10201/76901 consultada el 10 diciembre de 2019. 1-667.

Alejo Hernández Lavado Centro de Estudios Borjanos Fundación "Fernando el Católico" CSIC. Zaragoza ahernlav@unex.es https://orcid.org/oooo-0oo3-2648-6363 